\title{
Total Synthesis of Methyl 7-dihydro-trioxacarcinoside B
}

\author{
Christian M. König, Klaus Harms, Ulrich Koert ${ }^{*}$ \\ Fachbereich Chemie, Philipps-Universität Marburg, Hans-Meerwein-Strasse, 35043 Marburg, \\ Germany
}

\section{SUPPORTING INFORMATION}

\section{General Methods and Materials}

All non-aqueous reactions were carried out using flame-dried glassware under argon atmosphere. All solvents were distilled by rotary evaporation. Solvents for non-aqueous reactions were dried as follows prior to use: THF and $\mathrm{Et}_{2} \mathrm{O}$ were dried with $\mathrm{KOH}$ and subsequently distilled from sodium/benzophenone, respectively from a potassium/sodium alloy (K/Na 4:1). $\mathrm{CH}_{2} \mathrm{Cl}_{2}$ was distilled from $\mathrm{CaH}_{2} \cdot \mathrm{CHCl}_{3}$ (for measuring optical rotations) was dried by passage through basic alumina, $\mathrm{MeOH}$ was dried by refluxing with $\mathrm{Mg}$-turnings $(5 \mathrm{~g} / \mathrm{L})$ and subsequent distillation. All commercially available reagents and reactants were used without purification unless otherwise noted. Reactions were monitored by thin layer chromatography (TLC) using Merck Silica Gel $60 \mathrm{~F}_{245}$-plates and visualized by fluorescence quenching under UV-light. In addition, TLC-plates were stained using a cerium sulfate / phosphomolybdic acid stain. Chromatographic purification of products was performed on Merck Silica Gel 60 (230-400 mesh) unless otherwise noted using a forced flow of eluents. Concentration under reduced pressure was performed by rotary evaporation at $40{ }^{\circ} \mathrm{C}$ and appropriate pressure. Yields refer to purified and spectroscopically pure products unless otherwise noted. Optical rotations were measured on a Perkin-Elmer 241 polarimeter using dried solvents and a $1 \mathrm{dm}$ path length cell. IR spectra were recorded on a Bruker IFS 200 or a Nicolet Magna-IR 750 spectrometer. The absorption bands are given in wave numbers $\left(\mathrm{cm}^{-1}\right)$, intensities are reported as follows: $\mathrm{s}=$ strong, $\mathrm{m}=$ medium, $\mathrm{w}=$ weak, $\mathrm{br}=$ broad band. NMR-spectra were recorded on a Bruker ARX300 or DRX500 spectrometer at room temperature. Chemical shifts are reported in ppm with the solvent resonance as internal standard. Data are reported as follows: $\mathrm{s}=$ singlet, $\mathrm{d}=$ doublet, $\mathrm{t}=$ triplet, $\mathrm{qi}=$ quintet, $\mathrm{m}=$ multiplet, $\mathrm{m}_{\mathrm{c}}=$ symmetrical multiplet, $\mathrm{b}=$ broad signal and $\mathrm{p}=$ pseudo. Mass spectra were recorded on a Finnigan MAT TSQ 700 or MAT 95S (both mass service of PhilippsUniversität Marburg). 


\section{Experimental Procedures and Compound Characterization}

\section{(S)-4-hydroxy-3-methylen-pentan-2-one (7)}

\section{Baylis-Hillman-Reaction}

DABCO (5.98 g, $0.05 \mathrm{~mol})$ was dissolved in acetaldehyde $(27.40 \mathrm{~mL}, 0.49 \mathrm{~mol})$ and cooled to $0{ }^{\circ} \mathrm{C}$. At this temperature methylvinylketone $(40.00 \mathrm{~mL}, 0.49 \mathrm{~mol})$ was added via a dropping funnel over $9 \mathrm{~h}$. The mixture was stirred for $15 \mathrm{~h}$ at room temperature. $\mathrm{Et}_{2} \mathrm{O}(300 \mathrm{~mL})$ and $1 \mathrm{M}$ $\mathrm{HCl}$-solution $(50 \mathrm{~mL})$ were added. The aqueous solution was extracted with $\mathrm{Et}_{2} \mathrm{O}(2 \times 100$ $\mathrm{mL})$. The combined organic layers were washed with sat. $\mathrm{NaHCO}_{3}$-solution $(50 \mathrm{~mL})$. The aqueous layer was extracted with $\mathrm{Et}_{2} \mathrm{O}(2 \times 100 \mathrm{~mL})$ and dried with $\mathrm{Na}_{2} \mathrm{SO}_{4}$. Purification by distillation $\left(8 \mathrm{mbar}, 80^{\circ} \mathrm{C}\right)$ provided hydroxyl ketone as a colorless oil $(44.3 \mathrm{~g}, 0.39 \mathrm{~mol}$, $81 \%)$.

\section{Biocatalytic resolution}

To $4 \AA$ molecular sieve (3 g) and Pseudomonas Amano AK preparation (6 g) was added vinyl acetate $(29.07 \mathrm{~mL}, 315.4 \mathrm{mmol})$ and racemic hydroxy ketone $(18.00 \mathrm{~g}, 157.70 \mathrm{mmol})$ in hexane $(480 \mathrm{~mL})$. The suspension was rapidly stirred for $27 \mathrm{~h}$. Progress of this reaction was monitored by HPLC (Chiracel OD-H). The solid was filtered off and the filtrate was concentrated in vacuo. The residue was purified by flash chromatography (200 g silica gel, pentane/ $\left.\mathrm{Et}_{2} \mathrm{O} 5: 1 \rightarrow 1: 1\right)$ to yield enantiopure hydroxyl ketone 7 (7.18 g, $62.91 \mathrm{mmol}, 40 \%$, $>99 \%$ ee). Enantiomeric excess was determined by HPLC (Chiracel OD-H, hexane/iPrOH 99:1, 0.7 mL/min, $\mathrm{t}_{\mathrm{r}}[(R)]=37.1$ and $\left.\mathrm{t}_{\mathrm{r}}[(S)]=39.7\right) . \mathrm{R}_{\mathrm{f}}=0.5\left(\mathrm{Et}_{2} \mathrm{O}\right) .[\alpha]_{\mathrm{D}}=-3.66(\mathrm{c}=1.75$, $\left.\mathrm{CHCl}_{3}\right) .{ }^{1} \mathrm{H}-\mathrm{NMR}\left(300 \mathrm{MHz}, \mathrm{CDCl}_{3}\right): \delta=1.31(\mathrm{~d}, \mathrm{~J}=6.6 \mathrm{~Hz}, 3 \mathrm{H}), 2.34(\mathrm{~s}, 3 \mathrm{H}), 2.88$ (bs, $1 \mathrm{H}), 4.62(\mathrm{q}, \mathrm{J}=6.6 \mathrm{~Hz}, 1 \mathrm{H}), 6.03(\mathrm{~s}, 1 \mathrm{H}), 6.08(\mathrm{~s}, 1 \mathrm{H}) ;{ }^{13} \mathrm{C}-\mathrm{NMR}\left(75 \mathrm{MHz}, \mathrm{CDCl}_{3}\right): \delta=$ 22.1, 26.3, 66.4, 124.6 , 151.5, 200.6. IR (film): $\tilde{v}=3439$ (br), 2975 (m), 2931 (m), 1669 (s), 1367 (s), 1288 (m), 1088 (s), 970 (w); HRMS (EI): m/z: calcd. for $\mathrm{C}_{6} \mathrm{H}_{10} \mathrm{O}_{2}\left(\mathrm{M}^{+}\right)$: 114.0681, found: 114.0680 . 


\section{(S)-4-(tert-butyldimethylsilyloxy)-3-methylenepentan-2-one (8)}

Hydroxy ketone $7(1 \mathrm{~g}, 8.8 \mathrm{mmol})$ was dissolved in $\mathrm{CH}_{2} \mathrm{Cl}_{2}(50 \mathrm{~mL})$ then $\mathrm{TBSCl}(15.1 \mathrm{~mL}$, $43.8 \mathrm{mmol}, 2.9 \mathrm{M}$ in toluene) and imidazole $(2.98 \mathrm{~g}, 43.8 \mathrm{mmol})$ were added. The white suspension was stirred for $24 \mathrm{~h}$ at room temperature. Sat. $\mathrm{NH}_{4} \mathrm{Cl}$-solution $(50 \mathrm{~mL})$ was added. The aqueous solution was extracted with $\mathrm{CH}_{2} \mathrm{Cl}_{2}(3 \times 50 \mathrm{~mL})$ and dried with $\mathrm{Na}_{2} \mathrm{SO}_{4}$, concentrated and the residue was purified by flash chromatography (100 $\mathrm{g}$ silica gel, pentane/MTBE 20:1) to yield the corresponding silyl ether $8(1.9 \mathrm{~g}(8.3 \mathrm{mmol}, 95 \%)$ as a colorless oil. $\mathrm{R}_{\mathrm{f}}=0.68$ (pentane/MTBE 10:1). $[\alpha]_{\mathrm{D}}=-6.3\left(\mathrm{c}=1.35, \mathrm{CHCl}_{3}\right) .{ }^{1} \mathrm{H}-\mathrm{NMR}(300$ $\mathrm{MHz}, \mathrm{CDCl}_{3}$ ): $\delta=0.01$ (s, 3H), 0.05 (s, 3H), 0.89 (s, 9H), 1.20 (d, J = 6.2 Hz, 3H), 2.34 (s, $3 \mathrm{H}), 4.76(\mathrm{q}, \mathrm{J}=6.2 \mathrm{~Hz}, 1 \mathrm{H}), 6.06(\mathrm{~s}, 1 \mathrm{H}), 6.17(\mathrm{~s}, 1 \mathrm{H}) .{ }^{13} \mathrm{C}-\mathrm{NMR}\left(75 \mathrm{MHz}, \mathrm{CDCl}_{3}\right): \delta=$ -5.0, -4.9, 18.2, 24.8, 25.8, 26.4, 66.0, 124.1, 153.6, 199.2. IR (film): $\tilde{v}=2956$ (s), 2931 (s), 2887 (w), 2858 (s), 1679 (s), 1374 (m), 1363 (m), 1255 (s), 1089 (s), 1058 (w), 981 (s), 871 (w), 837 (s), 811 (w), 779 (m). HRMS (ESI): m/z: calcd. for $\mathrm{C}_{12} \mathrm{H}_{24} \mathrm{Na} \mathrm{O}_{2} \mathrm{Si}\left(\mathrm{M}+\mathrm{Na}^{+}\right)$: 251.1438, found: 251.1438 .

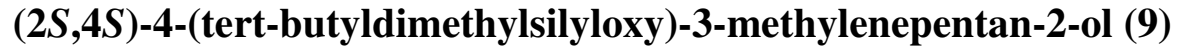

2,6-Di-tert-butyl-4-methylphenol (10.81 g, $49.04 \mathrm{mmol})$ was dissolved in toluene $(60 \mathrm{~mL})$ and cooled to $0{ }^{\circ} \mathrm{C}$. DIBAH $(22.68 \mathrm{~mL}, 22.68 \mathrm{mmol}, 1.0 \mathrm{M}$ in toluene) was added via a syringe over $5 \mathrm{~min}$. The colourless solution was stirred at this temperature for $1 \mathrm{~h}$, then transferred into a cooled dropping funnel at $-78^{\circ} \mathrm{C}$. This solution was added over $2 \mathrm{~h}$ to a solution of silyl ether $8(2.80 \mathrm{~g}, 12.26 \mathrm{mmol})$ in toluene $(90 \mathrm{~mL})$ at $-90{ }^{\circ} \mathrm{C}$. The yellow solution was warmed to $-78^{\circ} \mathrm{C}$ and stirred for $3.5 \mathrm{~h}$. The solution was allowed to warm to $-50{ }^{\circ} \mathrm{C}$ and then the cooling bath was removed. The solution was allowed to warm to $-7^{\circ} \mathrm{C}$ over $5 \mathrm{~h}$. The reaction mixture was added to a solution of Rochelles salt $(1 \mathrm{M}, 100 \mathrm{~mL})$ and diluted with ethyl acetate $(20 \mathrm{~mL})$. After $1 \mathrm{~h}$ stirring the layers were separated and the aqueous solution was extracted with ethyl acetate $(4 \times 50 \mathrm{~mL})$. The combined organic layers were dried with $\mathrm{Na}_{2} \mathrm{SO}_{4}$, concentrated and the residue was purified by flash chromatography $\left(100 \mathrm{~g}\right.$ silica gel, pentane/Et $\left.\mathrm{Et}_{2} \mathrm{O} 20: 1 \rightarrow 10: 1\right)$ to yield alcohol 9 (2.25 g, $9.77 \mathrm{mmol}, 80 \%$ diastereomeric mixture of 88:12 revealed by GC, $\mathrm{t}_{\mathrm{r}}[($ anti $)]=9.95 \mathrm{~min}$ and $\mathrm{t}_{\mathrm{r}}[(\mathrm{syn})]=10.19$ min, Hewlett-Packard 5890 Series II, Optima 5Ms, $0.25 \mu \mathrm{m}, 30 \mathrm{~m}$ x $0.25 \mathrm{~mm}$, FID, start temperature $50{ }^{\circ} \mathrm{C}, 50{ }^{\circ} \mathrm{C} / \mathrm{min}$ to $100{ }^{\circ} \mathrm{C}, 10{ }^{\circ} \mathrm{C} / \mathrm{min}$ to $120^{\circ} \mathrm{C}$, isotherm $8 \mathrm{~min}$, measurement period $12 \mathrm{~min}$, injector $250{ }^{\circ} \mathrm{C}$, detector $280{ }^{\circ} \mathrm{C}$, He $20 \mathrm{~mL} / \mathrm{min}, \mathrm{H}_{2} 30 \mathrm{~mL} / \mathrm{min}$, air $300 \mathrm{~mL} / \mathrm{min}$ ) as a colorless oil. The anti alcohol 9 and the syn alcohol 9a were separated by silica gel chromatography. Higher Rf compound, anti alcohol 9: $\mathrm{R}_{\mathrm{f}}=0.2$ (pentane/TBME 
10:1). $[\alpha]_{\mathrm{D}}=-41.54\left(\mathrm{c}=1.3, \mathrm{CHCl}_{3}\right) .{ }^{1} \mathrm{H}-\mathrm{NMR}\left(300 \mathrm{MHz}, \mathrm{CDCl}_{3}\right): \delta=0.08(\mathrm{~s}, 3 \mathrm{H}), 0.09(\mathrm{~s}$, $3 \mathrm{H}), 0.89(\mathrm{~s}, 9 \mathrm{H}), 1.23(\mathrm{~d}, \mathrm{~J}=6.4 \mathrm{~Hz}, 3 \mathrm{H}), 1.24(\mathrm{~d}, \mathrm{~J}=6.4 \mathrm{~Hz}, 3 \mathrm{H}), 4.36(\mathrm{q}, \mathrm{J}=6.4 \mathrm{~Hz}, 1 \mathrm{H})$, $4.41(\mathrm{q}, \mathrm{J}=6.4 \mathrm{~Hz}, 1 \mathrm{H}) 5.00(\mathrm{~s}, 1 \mathrm{H}), 5.02(\mathrm{~s}, 1 \mathrm{H}) .{ }^{13} \mathrm{C}-\mathrm{NMR}\left(75 \mathrm{MHz}, \mathrm{CDCl}_{3}\right): \delta=-5.0,-4.8$, 18.0, 21.6, 23.8, 25.8, 68.3, 73.1, 109.3, 154.3. IR (film): $\tilde{v}=3431$ (br), 2957 (s), 2931 (s), 2887 (m), 2858 (s), 1472 (m), 1483 (m), 1370 (m), 1256 (m), 1097 (s), 974 (m), 917 (w), 871 (w), 835 (s), 776 (s). HRMS (ESI): $m / z$ : calcd. for $\mathrm{C}_{12} \mathrm{H}_{26} \mathrm{O}_{2} \mathrm{NaSi}\left(\mathrm{M}+\mathrm{Na}^{+}\right)$: 253.1594, found: 253.1595. Lower Rf compound, syn alcohol 9a: $\mathrm{R}_{\mathrm{f}}=0.19$ (pentane/TBME 10:1). ${ }^{1} \mathrm{H}-\mathrm{NMR}$ $\left(300 \mathrm{MHz}, \mathrm{CDCl}_{3}\right): \delta=0.07$ (s, 3H), 0.09 (s, 3H), 0.90 (s, 9H), 1.33 (d, J=6.2 Hz, 3H), 1.35 $(\mathrm{d}, J=6.6 \mathrm{~Hz}, 3 \mathrm{H}), 4.41(\mathrm{q}, J=6.4 \mathrm{~Hz}, 1 \mathrm{H}), 4.47$ (q, $J=6.5 \mathrm{~Hz}, 1 \mathrm{H}) 5.03(\mathrm{~s}, 1 \mathrm{H}), 5.05$ (s, 1H). ${ }^{13} \mathrm{C}-\mathrm{NMR}\left(75 \mathrm{MHz}, \mathrm{CDCl}_{3}\right): \delta=-4.9,-4.3,18.1,22.6,24.6,25.8,68.1,71.3,108.8$, 156.1. IR (film): $\tilde{v}=3431$ (br), 2957 (s), 2931 (s), 2887 (m), 2858 (s), 1472 (m), 1483 (m), 1370 (m), 1256 (m), 1097 (s), 974 (m), 917 (w), 871 (w), 835 (s), 776 (s). HRMS (ESI): m/z: calcd. for $\mathrm{C}_{12} \mathrm{H}_{26} \mathrm{O}_{2} \mathrm{NaSi}\left(\mathrm{M}+\mathrm{Na}^{+}\right)$: 253.1594, found: 253.1595 .

\section{Assignment of the relative configuration of 9 via formation of the benzylidene acetals}

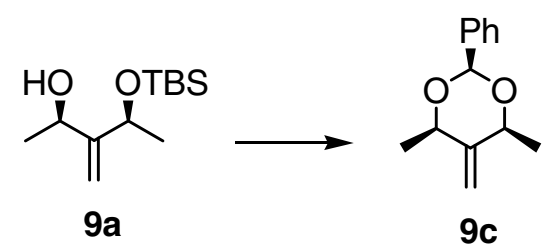

The syn-alcohol 9a (44 mg, $0.19 \mathrm{mmol})$ was dissolved in THF (5 mL) and TBAF-solution (1 $\mathrm{M}$ in THF, $0.38 \mathrm{~mL}, 0.38 \mathrm{mmol}$ ) was added. The solution was stirred for $2 \mathrm{~h}$ at room temperature. The solvent was removed and the residue was purified by flash chromatography (3 g silica gel, $\left.\mathrm{CHCl}_{3} / \mathrm{MeOH} 50: 1\right)$ to yield the corresponding meso diol (21.7 mg, $0.19 \mathrm{mmol}$, $98 \%)$ as a colourless oil. $\mathrm{R}_{\mathrm{f}}=0.24\left(\mathrm{CHCl}_{3} / \mathrm{MeOH} 10: 1\right) .{ }^{1} \mathrm{H}-\mathrm{NMR}\left(300 \mathrm{MHz}, \mathrm{CDCl}_{3}\right): \delta=$ $1.36(\mathrm{~d}, \mathrm{~J}=6.3 \mathrm{~Hz}, 6 \mathrm{H}), 2.80(\mathrm{bs}, 2 \mathrm{H}), 4.5(\mathrm{q}, \mathrm{J}=6.3 \mathrm{~Hz}, 2 \mathrm{H}), 5.07(\mathrm{~s}, 2 \mathrm{H}) .{ }^{13} \mathrm{C}-\mathrm{NMR}(75$ $\mathrm{MHz}, \mathrm{CDCl}_{3}$ ): $\delta=22.1,69.1,110.4$, 154.0. IR (film): $\tilde{\mathrm{v}}=3356$ (s), 2976 (m), $2932(\mathrm{~m}), 2882$ (m), 1454 (m), 1409 (m), 1371 (m), 1292 (m), 1087 (s), 1037 (m), 930 (m), 915 (m). Meso diol $(66 \mathrm{mg}, 0.57 \mathrm{mmol})$ was dissolved in $\mathrm{CH}_{2} \mathrm{Cl}_{2}(5 \mathrm{~mL})$ then benzaldehyde dimethyl acetal $(0.34 \mathrm{~mL}, 2.27 \mathrm{mmol})$ and $\mathrm{p}-\mathrm{TsOH}(11 \mathrm{mg}, 0.06 \mathrm{mmol})$ were added. The yellow solution was stirred for $12 \mathrm{~h}$ at room temperature. The solution was washed with sat. $\mathrm{NaHCO}_{3}$-solution $(5 \mathrm{~mL})$ and the aqueous phase was extracted with $\mathrm{CH}_{2} \mathrm{Cl}_{2}(3 \times 5 \mathrm{~mL})$. The combined organic phases were dried with $\mathrm{Na}_{2} \mathrm{SO}_{4}$ and the solvent was removed in vacuo. The crude product was purified by flash chromatography (8 g silica gel, pentane/TBME 30:1) to yield the acetal 9c (112 mg, $0.55 \mathrm{mmol}, 97 \%)$ as a colourless liquid. $\mathrm{R}_{\mathrm{f}}=0.46$ (pentane/TBME 10:1). ${ }^{1} \mathrm{H}-\mathrm{NMR}\left(300 \mathrm{MHz}, \mathrm{CDCl}_{3}\right): \delta=1.48$ $(\mathrm{d}, \mathrm{J}=6.3 \mathrm{~Hz}, 6 \mathrm{H}), 4.5(\mathrm{q}, \mathrm{J}=6.3 \mathrm{~Hz}, 2 \mathrm{H}), 5.05(\mathrm{~s}, 2 \mathrm{H}), 5.80(\mathrm{~s}, 1 \mathrm{H}), 7.33-7.43(\mathrm{~m}, 5 \mathrm{H}) .{ }^{13} \mathrm{C}-$ 
NMR (75 MHz, $\left.\mathrm{CDCl}_{3}\right): \delta=17.2,74.8,101.3,107.1,126.3,128.3,128.8,129.0,147.7$.

HRMS (ESI): $m / z$ calcd. for $\mathrm{C}_{13} \mathrm{H}_{16} \mathrm{NaO}_{2}\left(\mathrm{M}+\mathrm{Na}^{+}\right): 227.1043$, found: 227.1045.

The phenyl- and both methyl-substituents are located in equatorial position in 9c. Only one ${ }^{1}$ H-NMR-signal was observed for both methyl groups.

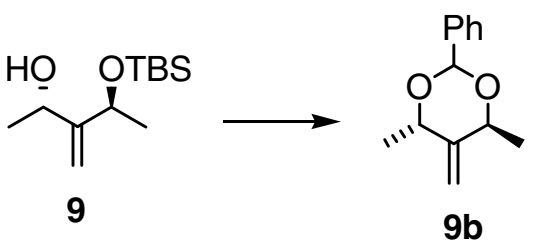

Staring from the anti alcohol $\mathbf{9}$ the benzylidene acetal $\mathbf{9 b}$ was prepared according the procedure for the conversion of $9 \mathbf{a}$ to $9 \mathbf{c}$.

9b: $\mathrm{R}_{\mathrm{f}}=0.46$ (pentane/TBME 10:1). ${ }^{1} \mathrm{H}-\mathrm{NMR}\left(300 \mathrm{MHz}, \mathrm{CDCl}_{3}\right): \delta=1.46(\mathrm{~d}, \mathrm{~J}=6.3 \mathrm{~Hz}$, $3 \mathrm{H}), 1.54(\mathrm{~d}, \mathrm{~J}=6.9 \mathrm{~Hz}, 1 \mathrm{H}), 4.7(\mathrm{q}, \mathrm{J}=6.3 \mathrm{~Hz}, 2 \mathrm{H}), 4.76(\mathrm{q}, \mathrm{J}=6.9 \mathrm{~Hz}, 1 \mathrm{H}), 4.97$ (s, 2H), $5.98(\mathrm{~s}, 2 \mathrm{H}), 7.32-7.43(\mathrm{~m}, 5 \mathrm{H}) .{ }^{13} \mathrm{C}-\mathrm{NMR}\left(75 \mathrm{MHz}, \mathrm{CDCl}_{3}\right): \delta=18.2,18.9,71.4,73.5,95.2$, 108.3, 126.3, 128.3, 130.0, 138.6, 147.7. HRMS (ESI): $m / z$ calcd. for $\mathrm{C}_{13} \mathrm{H}_{16} \mathrm{NaO}_{2}\left(\mathrm{M}+\mathrm{Na}^{+}\right)$: 227.1043, found: 227.1045 .

One methyl-residue occupies an axial and the other an equatorial position. Two ${ }^{1} \mathrm{H}-\mathrm{NMR}-$ signal was observed for the two methyl groups in $\mathbf{9 b}$.

\section{$(2 S, 4 S)$-but-3-enoic acid 3-(tert-butyl-dimethyl-silanyloxy)-1-methyl-2-methylene-butyl ester (10)}

Alcohol $9(0.10 \mathrm{~g}, 0.43 \mathrm{mmol})$ was dissolved in toluene $(5 \mathrm{~mL})$ and cooled to $0{ }^{\circ} \mathrm{C}$. Vinylacetic acid $(0.18 \mathrm{~mL}, 2.17 \mathrm{mmol})$ and DMAP $(5 \mathrm{mg}, 43.4 \mu \mathrm{mol})$ were added. DCC $(0.18 \mathrm{~g}, 0.87 \mathrm{mmol})$ was added in 2 portions over $2 \mathrm{~min}$. The white suspension was stirred at $0{ }^{\circ} \mathrm{C}$ for $30 \mathrm{~min}$, then warmed to room temperature and stirred for $2 \mathrm{~h}$. The precipitated urea was filtered off and sat. $\mathrm{NaHCO}_{3}$-solution $(25 \mathrm{~mL})$ was added. The aqueous solution was extracted with $\mathrm{CH}_{2} \mathrm{Cl}_{2}(2 \times 100 \mathrm{~mL})$. The combined organic layers were washed with sat. $\mathrm{NH}_{4} \mathrm{Cl}$-solution $(25 \mathrm{~mL})$ and the aqueous layer was extracted with $\mathrm{CH}_{2} \mathrm{Cl}_{2}(2 \times 100 \mathrm{~mL})$. The combined organic layers were dried with $\mathrm{Na}_{2} \mathrm{SO}_{4}$ and concentrated. The residue was purified by flash chromatography (10 g silica gel, pentane/Et $\left.\mathrm{t}_{2} \mathrm{O} 20: 1\right)$ to yield TBS-protected ester 10 $(0.128 \mathrm{~g}, 0.43 \mathrm{mmol}, 99 \%)$ as a colourless oil. $\mathrm{R}_{\mathrm{f}}=0.56$ (pentane/TBME 10:1). $[\alpha]_{\mathrm{D}}=-41.54$ $\left(\mathrm{c}=1.3, \mathrm{CHCl}_{3}\right) .{ }^{1} \mathrm{H}-\mathrm{NMR}\left(300 \mathrm{MHz}, \mathrm{CDCl}_{3}\right): \delta=-0.03(\mathrm{~s}, 3 \mathrm{H}),-0.05(\mathrm{~s}, 3 \mathrm{H}), 0.88(\mathrm{~s}, 9 \mathrm{H})$, $1.27(\mathrm{~d}, \mathrm{~J}=6.2 \mathrm{~Hz}, 3 \mathrm{H}), 1.35(\mathrm{~d}, \mathrm{~J}=6.6 \mathrm{~Hz}, 3 \mathrm{H}), 3.08(\mathrm{dt}, \mathrm{J}=1.4,7.0 \mathrm{~Hz}, 2 \mathrm{H}), 4.27$ (q, J =

$6.3 \mathrm{~Hz}, 1 \mathrm{H}), 5.08-5.19(\mathrm{~m}, 4 \mathrm{H}), 5.33(\mathrm{q}, \mathrm{J}=6.6 \mathrm{~Hz}, 1 \mathrm{H}), 5.85-5.99(\mathrm{~m}, 1 \mathrm{H}) .{ }^{13} \mathrm{C}-\mathrm{NMR}(75$ $\left.\mathrm{MHz}, \mathrm{CDCl}_{3}\right): \delta=-4.9(2 \mathrm{x}), 18.1,20.9,24.3,25.8,39.4,69.1,70.2,109.0,118.5,130.3$, 
153.6, 170.5. IR (film): $\tilde{v}=2957$ (s), 2931 (s), 2887 (m), 2858 (s), 1739 (s), 1472 (w), 1463 (w), 1373 (w), 1336 (w), 1282 (w), 1254 (s), 1174 (s), 1082 (s), 1054 (m), 1029 (w), 1006 (w), 973 (m), 919 (w), 835 (s), 777 (m). HRMS (ESI): m/z calcd. for $\mathrm{C}_{16} \mathrm{H}_{30} \mathrm{NaO}_{3} \mathrm{Si}\left(\mathrm{M}+\mathrm{Na}^{+}\right)$: 321.1856, found: 321.1855 .

\section{Hex-3-enedioic acid bis-(3-hydroxy-1-methyl-2-methylene-butyl) ester (11)}

TBS-protected ester $10(21 \mathrm{mg}, 0.07 \mathrm{mmol})$ was dissolved in $\mathrm{CH}_{2} \mathrm{Cl}_{2}(5 \mathrm{~mL})$ and Grubbs 2 catalyst $(10 \mathrm{mg}, 0.01 \mathrm{mmol})$ was added. The tube was sealed and stirred for $120 \mathrm{~h}$ at $45{ }^{\circ} \mathrm{C}$. The solvent was removed in vacuo and the residue was purified by flash chromatography ( $3 \mathrm{~g}$ silica gel, pentane/ $\left.\mathrm{Et}_{2} \mathrm{O} 20: 1\right)$ to yield dimer 11 (12.6 mg, $0.02 \mathrm{mmol}, 63 \%$, E/Z-mixture 1:1) as a brown oil. $\mathrm{R}_{\mathrm{f}}=0.31$ (pentane/TBME 10:1). ${ }^{1} \mathrm{H}-\mathrm{NMR}\left(300 \mathrm{MHz}, \mathrm{CDCl}_{3}\right): \delta=-0.05-$ - $0.03(\mathrm{~m}, 12 \mathrm{H}), 0.89\left(\mathrm{~m}_{\mathrm{c}}, 18 \mathrm{H}\right), 1.24-1.28(\mathrm{~m}, 6 \mathrm{H}), 1.34-1.38(\mathrm{~m}, 6 \mathrm{H}), 3.06-3.11(\mathrm{~m}, 4 \mathrm{H})$, 4.24-4.35 (m, 2H), 5.08-5.19 (m, 4H), 5.28-5.41 (m, 2H), $5.70\left(\mathrm{~m}_{\mathrm{c}}, 2 \mathrm{H}\right)$. IR (film): $\tilde{v}=2956$ (s), 2931 (s), 2894 (m), 2857 (s), 1739 (s), 1654 (w), 1472 (w), 1463 (w), 1372 (m), 1255 (s), 1170 (m), 1081 (s), 1169 (m), 1081 (s), 1053 (m), 1027 (m), 973 (s), 915 (w), 835 (s), 777 (m), 671 (w). HRMS (ESI): $m / z$ calcd. for $\mathrm{C}_{30} \mathrm{H}_{56} \mathrm{NaO}_{3} \mathrm{Si}_{2}\left(\mathrm{M}+\mathrm{Na}^{+}\right)$: 591.3508, found: 591.3515 .

\section{(2S,4S)-4-hydroxy-3-methylenepentan-2-yl-but-3-enoate (12)}

Alcohol $9(2.24 \mathrm{~g}, 9.72 \mathrm{mmol})$ was dissolved in toluene $(80 \mathrm{~mL})$ and cooled to $0{ }^{\circ} \mathrm{C}$. Vinylacetic acid $(4.13 \mathrm{~mL}, 48.61 \mathrm{mmol})$ and DMAP $(0.12 \mathrm{~g}, 0.97 \mathrm{mmol})$ were added. DCC (4.01 g, $19.44 \mathrm{mmol}$ ) was added in 5 portions over $2 \mathrm{~min}$. The white suspension was stirred at $0{ }^{\circ} \mathrm{C}$ for $30 \mathrm{~min}$, then warmed to room temperature and stirred for $2 \mathrm{~h}$. The precipitated urea was filtered off and sat. $\mathrm{NaHCO}_{3}$-solution $(125 \mathrm{~mL})$ was added. The aqueous solution was extracted with $\mathrm{CH}_{2} \mathrm{Cl}_{2}(2 \times 100 \mathrm{~mL})$. The combined organic layers were washed with sat. $\mathrm{NH}_{4} \mathrm{Cl}$-solution $(125 \mathrm{~mL})$ and the aqueous layer was extracted with $\mathrm{CH}_{2} \mathrm{Cl}_{2}(2 \times 100 \mathrm{~mL})$. The combined organic layers were dried with $\mathrm{Na}_{2} \mathrm{SO}_{4}$ and concentrated. The crude product was treated with aqueous $5 \% \mathrm{HF}$ in $\mathrm{CH}_{3} \mathrm{CN}(150 \mathrm{ml})$. The solution was stirred for $2 \mathrm{~h}$ at room temperature. Sat. $\mathrm{NaHCO}_{3}$-solution $(150 \mathrm{~mL})$ was added carefully, then solid $\mathrm{NaHCO}_{3}$ was added until precipitation. The organic layer was separated and the aqueous layer was extracted with ethyl acetate $(4 \times 100 \mathrm{~mL})$. The combined organic layers were dried with $\mathrm{Na}_{2} \mathrm{SO}_{4}$, concentrated and the residue was purified by flash chromatography (150 g silica gel, pentane/Et $\mathrm{Et}_{2} \mathrm{O}$ 2:1) to yield ester $12(1.76 \mathrm{~g}, 9.56 \mathrm{mmol}, 98 \%)$ as a colourless oil. $\mathrm{R}_{\mathrm{f}}=0.1$ (pentane/TBME 10:1). $[\alpha]_{\mathrm{D}}=-72.2\left(\mathrm{c}=1.0, \mathrm{CHCl}_{3}\right) .{ }^{1} \mathrm{H}-\mathrm{NMR}\left(300 \mathrm{MHz}, \mathrm{CDCl}_{3}\right): \delta=1.29$ 
$(\mathrm{d}, \mathrm{J}=6.6 \mathrm{~Hz}, 3 \mathrm{H}), 1.39$ (d, J = 6.6 Hz, 3H), 2.69 (bs, 1H), 3.08 (d, J = 7.4 Hz, 2H), 4.33 (q, J $=6.6 \mathrm{~Hz}, 1 \mathrm{H}), 5.12-5.18(\mathrm{~m}, 4 \mathrm{H}), 5.32(\mathrm{q}, \mathrm{J}=6.6 \mathrm{~Hz}, 1 \mathrm{H}), 5.82-5.96(\mathrm{~m}, 1 \mathrm{H}) .{ }^{13} \mathrm{C}-\mathrm{NMR}(75$ $\mathrm{MHz}, \mathrm{CDCl}_{3}$ ): $\delta=21.0,22.5,39.4,69.0,69.8,110.9,118.8,129.9,153.4,171.2$. IR (film): $\tilde{v}=3441(\mathrm{~s}), 3084(\mathrm{w}), 2981$ (s), 2935 (m), 1735 (s), 1644 (m), 1454 (m), 1405 (m), 1374 (m), 1341 (m), 1258 (s), 1178 (s), 1083 (s), 1030 (m), 994 (m), 968 (w), 942 (s), 848 (w), 618 (w). HRMS (ESI): $m / z$ calcd. for $\mathrm{C}_{10} \mathrm{H}_{16} \mathrm{NaO}_{3}\left(\mathrm{M}+\mathrm{Na}^{+}\right)$: 207.0992, found: 207.0995 .

\section{(S)5-((S)-1-hydroxyethyl)-6-methyl-3,6-dihydro-2H-pyran-2-one (13)}

Ester 12 (1.25 g, $6.79 \mathrm{mmol})$ was dissolved in toluene $(900 \mathrm{~mL})$ and refluxed for $20 \mathrm{~min}$. Grubbs $2(0.29 \mathrm{~g}, 0.34 \mathrm{mmol})$ in $\mathrm{CH}_{2} \mathrm{Cl}_{2}(20 \mathrm{~mL})$ was added via a syringe. The solution was stirred at this temperature for $5 \mathrm{~h}$, then cooled to room temperature and stirred for $12 \mathrm{~h}$. The solvent was removed and the residue was purified by flash chromatography ( $150 \mathrm{~g}$ silica gel, pentane/Et $\left.\mathrm{E}_{2} \mathrm{O} 9: 1\right)$ to yield lactone $13(0.78 \mathrm{~g}, 5.02 \mathrm{mmol}, 74 \%)$ as a brownish oil. $\mathrm{R}_{\mathrm{f}}=0.2$ $\left(\mathrm{Et}_{2} \mathrm{O}\right) .[\alpha]_{\mathrm{D}}=75.6\left(\mathrm{c}=0.25, \mathrm{CHCl}_{3}\right) .{ }^{1} \mathrm{H}-\mathrm{NMR}\left(300 \mathrm{MHz}, \mathrm{CDCl}_{3}\right): \delta=1.33(\mathrm{~d}, \mathrm{~J}=6.4 \mathrm{~Hz}$, $3 \mathrm{H}), 1.49(\mathrm{~d}, \mathrm{~J}=6.8 \mathrm{~Hz}, 3 \mathrm{H}), 2.20(\mathrm{bs}, 1 \mathrm{H}), 3.07(\mathrm{~d}, \mathrm{~J}=3.1 \mathrm{~Hz}, 2 \mathrm{H}), 4.34(\mathrm{q}, \mathrm{J}=6.2 \mathrm{~Hz}$,

$1 \mathrm{H}), 5.00(\mathrm{q}, \mathrm{J}=6.7 \mathrm{~Hz}, 1 \mathrm{H}), 5.81(\mathrm{t}, \mathrm{J}=3.5 \mathrm{~Hz}, 1 \mathrm{H}) .{ }^{13} \mathrm{C}-\mathrm{NMR}\left(75 \mathrm{MHz}, \mathrm{CDCl}_{3}\right): \delta=21.4$, 22.6, 29.9, 67.2, 77.6, 115.1, 143.5, 170.8. IR (film): $\tilde{v}=3440$ (s), 2978 (m), 1735 (s), 1455 (w), 1376 (m), 1222 (m), 1162 (m), 1088 (m), 1042 (m), 1003 (w), 943 (w), 890 (w), 818 (w), 655 (w), 602 (w). HRMS (ESI): $m / z$ calcd. for for $\mathrm{C}_{8} \mathrm{H}_{12} \mathrm{NaO}_{3}\left(\mathrm{M}+\mathrm{Na}^{+}\right): 179.0679$, found: 179.0680 .

\section{(1S)-1-((2S)-6-methoxy-2-methyl-5,6-dihydro-2H-pyran-3-yl)ethanol (14)}

Lactone $13(0.43 \mathrm{~g}, 2.75 \mathrm{mmol})$ was dissolved in a mixture of toluene $(20 \mathrm{~mL})$ and $\mathrm{CH}_{2} \mathrm{Cl}_{2}$ $(5 \mathrm{~mL})$ and cooled to $-78{ }^{\circ} \mathrm{C}$. DIBAH $(3.67 \mathrm{~mL}, 5.51 \mathrm{mmol}, 1.5 \mathrm{M}$ in toluene) was added slowly via a syringe. The reaction was stirred for $6 \mathrm{~h}$ at this temperature. The reaction mixture was added to a solution of Rochelles salt $(1 \mathrm{M}, 20 \mathrm{~mL})$ and diluted with ethyl acetate $(20 \mathrm{~mL})$. After $1 \mathrm{~h}$ stirring the layers were separated and the aqueous solution was extracted with $\mathrm{CHCl}_{3} / i \mathrm{PrOH}$ 6:1 (15 x $\left.20 \mathrm{~mL}\right)$. The combined organic layers were dried with $\mathrm{Na}_{2} \mathrm{SO}_{4}$ and concentrated. The residue was dissolved in $\mathrm{MeOH}(10 \mathrm{~mL})$ and CSA (50 mg) was added. The reaction was stirred for $12 \mathrm{~h}$ at $20^{\circ} \mathrm{C}$. The solvent was evaporated and the residue was separated between $\mathrm{CH}_{2} \mathrm{Cl}_{2}(10 \mathrm{~mL})$ and $\mathrm{NaHCO}_{3}(5 \mathrm{~mL})$. The layers were separated and the aqueous layer was extracted with $\mathrm{CH}_{2} \mathrm{Cl}_{2}(10 \mathrm{~mL})$. The combined organic layers were dried with $\mathrm{Na}_{2} \mathrm{SO}_{4}$ and concentrated. to yield methyl glycoside 14 (0.43 g, $2.50 \mathrm{mmol}, 91 \%$, anomeric mixture ax:eq 1.4:1 revealed by $\left.{ }^{1} \mathrm{H}-\mathrm{NMR}\right)$ as a light yellow oil. $\mathrm{R}_{\mathrm{f}}=0.4\left(\mathrm{Et}_{2} \mathrm{O}\right)$. 
$[\alpha]_{D}=-102.18\left(\mathrm{c}=1.1, \mathrm{CHCl}_{3}\right) .{ }^{1} \mathrm{H}-\mathrm{NMR}\left(300 \mathrm{MHz}, \mathrm{CDCl}_{3}\right): \delta=1.24-1.34(\mathrm{~m}, 6 \mathrm{H}), 2.04-$ $2.46(\mathrm{~m}, 2 \mathrm{H}), 3.41+3.48(\mathrm{~s}, 3 \mathrm{H}), 4.25-4.34(\mathrm{~m}, 2 \mathrm{H}), 4.53+4.81\left(\mathrm{~m}_{\mathrm{c}}, 1 \mathrm{H}\right), 5.70-5.74(\mathrm{~m}, 1 \mathrm{H})$.

${ }^{13} \mathrm{C}-\mathrm{NMR}\left(75 \mathrm{MHz}, \mathrm{CDCl}_{3}\right): \delta=19.2+20.0,23.0+23.1,29.9+30.5,55.1+55.9,65.1+66.9$, 67.2+71.0, 96.3+99.5, 113.9+114.9, 143.2+144.3. IR (film): $\tilde{v}=3436$ (s), 2976 (m), 2933 (m), 2837 (m), 1652 (w), 1449 (m), 1366 (m), 1225 (m), 1180 (m), 1133 (m), 1052 (m), 1009 (m), 941 (w), 887 (m), 847 (w). HRMS (ESI): $m / z$ calcd. for $\mathrm{C}_{9} \mathrm{H}_{16} \mathrm{NaO}_{3}\left(\mathrm{M}+\mathrm{Na}^{+}\right): 195.0992$, found 195.0997.

\section{(1S)-1-((1R, 2S,6S)-4-methoxy-2-methyl-3,7-dioxabicyclo[4.1.0]heptan-1-yl)ethanol (16)}

Methylglycoside $14(0.43 \mathrm{~g}, 2.48 \mathrm{mmol})$ was dissolved in toluene $(20 \mathrm{~mL})$ and $\mathrm{VO}(\mathrm{acac})_{2}$ $(0.07 \mathrm{~g}, 0.28 \mathrm{mmol})$ and $t \mathrm{BuOOH}$ in decane $(5.5 \mathrm{M}, 0.50 \mathrm{~mL}, 2.75 \mathrm{mmol})$ were added. The dark red solution was stirred for $1 \mathrm{~h}$ at room temperature, then the reaction mixture was added to a sat. $\mathrm{Na}_{2} \mathrm{SO}_{3}$-solution $(30 \mathrm{~mL})$. After $1 \mathrm{~h}$ stirring, the layers were separated and the aqueous solution was extracted with ethyl acetate $(5 \times 30 \mathrm{~mL})$. The combined organic layers were dried with $\mathrm{Na}_{2} \mathrm{SO}_{4}$, the solvent was removed. The residue was purified by flash chromatography (40 g silica gel, pentane/ $\mathrm{Et}_{2} \mathrm{O} 2: 1$ ) and gave the two separated anomers 16 as colourless oils (0.36 g, $1.92 \mathrm{mmol}, 78 \%)$. Higher Rf compound, $\alpha$-anomer: $\mathrm{R}_{\mathrm{f}}=0.7\left(\mathrm{Et}_{2} \mathrm{O}\right)$. $[\alpha]_{\mathrm{D}}=-135.46\left(\mathrm{c}=1.23, \mathrm{CHCl}_{3}\right) .{ }^{1} \mathrm{H}-\mathrm{NMR}\left(300 \mathrm{MHz}, \mathrm{CDCl}_{3}\right): \delta=1.23(\mathrm{~d}, \mathrm{~J}=6.6 \mathrm{~Hz}, 3 \mathrm{H})$, $1.25(\mathrm{~d}, \mathrm{~J}=6.8 \mathrm{~Hz}, 3 \mathrm{H}), 1.88(\mathrm{ddd}, \mathrm{J}=1.7 \mathrm{~Hz}, 5.1 \mathrm{~Hz}, 15.7 \mathrm{~Hz}, 1 \mathrm{H}), 2.1(\mathrm{dd}, \mathrm{J}=4.9 \mathrm{~Hz}$, $15.7 \mathrm{~Hz}, 1 \mathrm{H}), 2.24$ (bs, 1H) $3.32(\mathrm{~s}, 3 \mathrm{H}), 3.39$ (d, J = 4.9 Hz, 1H), 3.91 (q, J = 6.4 Hz, 1H), $4.05(\mathrm{q}, \mathrm{J}=6.5 \mathrm{~Hz}, 1 \mathrm{H}), 4.56(\mathrm{~d}, \mathrm{~J}=4.4 \mathrm{~Hz}, 1 \mathrm{H}) .{ }^{13} \mathrm{C}-\mathrm{NMR}\left(75 \mathrm{MHz}, \mathrm{CDCl}_{3}\right): \delta=15.9,18.7$, 28.9, 51.2, 55.0, 61.6, 62.5, 63.4, 94.9. IR (film): $\tilde{v}=3444$ (br, s), 2981 (s), 2937 (s), 1448 (m), 1364 (m), 1203 (w), 1132 (m), 1055 (s), 1032 (m), 1009 (m), 880 (w), 798 (w), 679 (w), 646 (w). HRMS (ESI): $m / z$ calcd. for $\mathrm{C}_{9} \mathrm{H}_{16} \mathrm{NaO}_{4}\left(\mathrm{M}+\mathrm{Na}^{+}\right)$: 211.0941, found 211.0940. Lower Rf compound, $\beta$-anomer: $\mathrm{R}_{\mathrm{f}}=0.4\left(\mathrm{Et}_{2} \mathrm{O}\right) .[\alpha]_{\mathrm{D}}=28.13\left(\mathrm{c}=1.28, \mathrm{CHCl}_{3}\right) .{ }^{1} \mathrm{H}-\mathrm{NMR}$ $\left(300 \mathrm{MHz}, \mathrm{CDCl}_{3}\right): \delta=1.24(\mathrm{~d}, \mathrm{~J}=6.4 \mathrm{~Hz}, 3 \mathrm{H}), 1.33(\mathrm{~d}, \mathrm{~J}=6.4 \mathrm{~Hz}, 3 \mathrm{H}), 1.93(\mathrm{dd}, \mathrm{J}=9.1$ Hz, 15.3 Hz, 1H), 2.8 (ddd, J = 4.1 Hz, $5.4 \mathrm{~Hz}, 15.4 \mathrm{~Hz}, 1 \mathrm{H}), 2.14$ (bs, 1H), 3.42 (s, 3H), 3.38 $(\mathrm{d}, \mathrm{J}=5.5 \mathrm{~Hz}, 1 \mathrm{H}), 3.99(\mathrm{q}, \mathrm{J}=6.4 \mathrm{~Hz}, 1 \mathrm{H}), 4.00(\mathrm{q}, \mathrm{J}=6.2 \mathrm{~Hz}, 1 \mathrm{H}), 4.27(\mathrm{dd}, \mathrm{J}=$ $4.1 \mathrm{~Hz}, 9.0 \mathrm{~Hz}, 1 \mathrm{H}) .{ }^{13} \mathrm{C}-\mathrm{NMR}\left(75 \mathrm{MHz}, \mathrm{CDCl}_{3}\right): \delta=16.3,18.9,29.6,52.0,55.9,62.6,63.0$, 68.0, 99.5. IR (film): $\tilde{v}=3447$ (br, s), 2980 (s), 2935 (s), 1447 (m), 1384 (s), 1266 (w), 1206 (w) 1148 (m), 1136 (w), 1069 (s), 1050 (m), 890 (m), 873. HRMS (ESI): m/z calcd. for $\mathrm{C}_{9} \mathrm{H}_{16} \mathrm{NaO}_{4}\left(\mathrm{M}+\mathrm{Na}^{+}\right): 211.0941$, found 211.0944. 
Epoxide $16(0.11 \mathrm{~g}, 0.58 \mathrm{mmol})$ was dissolved in allyl alcohol $(5 \mathrm{~mL})$ and perchloric acid $(70 \%, 0.18 \mathrm{~mL}, 2.92 \mathrm{mmol})$ was added dropwise. The solution was stirred for $6 \mathrm{~h}$ at room temperature. The solution was diluted with $\mathrm{CH}_{2} \mathrm{Cl}_{2}(20 \mathrm{~mL})$ and a sat. $\mathrm{Na}_{2} \mathrm{SO}_{3}$-solution (20 $\mathrm{mL})$ was added. The organic layer was extracted with $\mathrm{CH}_{2} \mathrm{Cl}_{2}(5 \times 20 \mathrm{~mL})$. The combined organic layers were dried with $\mathrm{Na}_{2} \mathrm{SO}_{4}$, the solvent was removed and the residue was purified by flash chromatography ( $20 \mathrm{~g}$ silica gel, pentane/Et $\mathrm{t}_{2} \mathrm{O} 2: 1$ ) to yield the allyl ether 22 as a semi-solid (53 mg, $24.74 \mathrm{mmol}, 42 \%) . \mathrm{R}_{\mathrm{f}}=0.6\left(\mathrm{Et}_{2} \mathrm{O}\right) .[\alpha]_{\mathrm{D}}=-151.3\left(\mathrm{c}=1.0, \mathrm{CHCl}_{3}\right) .{ }^{1} \mathrm{H}-$ $\operatorname{NMR}\left(300 \mathrm{MHz}, \mathrm{CDCl}_{3}\right): \delta=1.23(\mathrm{~d}, \mathrm{~J}=6.6 \mathrm{~Hz}, 3 \mathrm{H}), 1.28(\mathrm{~d}, \mathrm{~J}=6.4 \mathrm{~Hz}, 3 \mathrm{H}), 1.96(\mathrm{ddd}, \mathrm{J}=$ $1.4 \mathrm{~Hz}, 3.8 \mathrm{~Hz}, 13.8 \mathrm{~Hz}, 1 \mathrm{H}), 2.38$ (ddd, J = 2.9 Hz, $9.4 \mathrm{~Hz}, 14.0 \mathrm{~Hz}, 1 \mathrm{H}$ ), 3.90 (dd, J = $3.9 \mathrm{~Hz}, 9.2 \mathrm{~Hz}, 1 \mathrm{H}), 3.97(\mathrm{ddpt}, \mathrm{J}=1.3 \mathrm{~Hz}, 5.9 \mathrm{~Hz}, 12.6 \mathrm{~Hz}, 1 \mathrm{H}), 4.14$ (ddpt, J = $1.4 \mathrm{~Hz}$, $5.3 \mathrm{~Hz}, 12.6 \mathrm{~Hz}, 1 \mathrm{H}), 4.31$ (q, $\mathrm{J}=6.5 \mathrm{~Hz}, 1 \mathrm{H}), 4.47(\mathrm{q}, \mathrm{J}=6.5 \mathrm{~Hz}, 1 \mathrm{H}), 4.91(\mathrm{dd}, \mathrm{J}=$ $1.1 \mathrm{~Hz}, 2.3 \mathrm{~Hz}, 1 \mathrm{H}), 5.93\left(\mathrm{~m}_{\mathrm{c}}, 1 \mathrm{H}\right) .{ }^{13} \mathrm{C}-\mathrm{NMR}\left(75 \mathrm{MHz}, \mathrm{CDl}_{3}\right): \delta=14.2,14.7,36.4,67.9$, 68.9, 69.4, 70.0, 71.1, 91.0, 117.6, 134.3. IR (film): $\tilde{v}=3447$ (br, s), 2977 (w), 2937 (w), 2359 (w), 1653 (m), 1559 (w), 1540 (w), 1521 (w), 1272 (w), 1101 (m), 1061 (m), 1030 (m), 945 (w), $826(w)$.

\section{(1R, 3S, 4R, 5S, 8R)-3,5-dimethyl-2,6-dioxabicyclo[2.2.2]octane-4,8-diol (23)}

Allyl ether $22(19.0 \mathrm{mg}, 69.8 \mu \mathrm{m})$ was dissolved in $\mathrm{MeOH} / \mathrm{CH}_{2} \mathrm{Cl}_{2} 3: 2$ (1 mL) and $\mathrm{PdCl}_{2}$ $(49.5 \mathrm{mg}, 279.1 \mu \mathrm{m})$ was added. The dark brown suspension was stirred at room temperature for $2 \mathrm{~h}$. Toluene $(1 \mathrm{~mL})$ was added, then $\mathrm{MeOH}$ and $\mathrm{CH}_{2} \mathrm{Cl}_{2}$ was removed in vacuo. The reaction mixture was directly purified by flash chromatography (2 g silica gel, $\mathrm{CH}_{2} \mathrm{Cl}_{2}$ 100:3) to afford anhydrosugar $23(4.0 \mathrm{mg}, 23.0 \mu \mathrm{m}, 33 \%)$ as a white solid. $\mathrm{R}_{\mathrm{f}}=0.36\left(\mathrm{CH}_{2} \mathrm{Cl}_{2} / \mathrm{MeOH}\right.$ 10:1). $[\alpha]_{\mathrm{D}}=-137.0\left(\mathrm{c}=1, \mathrm{H}_{2} \mathrm{O}\right) .{ }^{1} \mathrm{H}-\mathrm{NMR}\left(300 \mathrm{MHz}, \mathrm{CDCl}_{3}\right): \delta=1.24(\mathrm{~d}, \mathrm{~J}=6.6 \mathrm{~Hz}, 3 \mathrm{H})$, $1.29(\mathrm{~d}, \mathrm{~J}=6.4 \mathrm{~Hz}, 3 \mathrm{H}), 1.92(\mathrm{ddd}, \mathrm{J}=1.5 \mathrm{~Hz}, 3.8 \mathrm{~Hz}, 14.2 \mathrm{~Hz}, 1 \mathrm{H}), 2.51$ (ddd, J = 2.6 Hz, $9.8 \mathrm{~Hz}, 14.6 \mathrm{~Hz}, 1 \mathrm{H}), 4.27$ (dd, J = 3.7 Hz, $9.9 \mathrm{~Hz}, 1 \mathrm{H}), 4.29$ (q, J = 6.7 Hz, 1H), 4.49 (q, J = $6.4 \mathrm{~Hz}, 1 \mathrm{H}), 4.89(\mathrm{dd}, \mathrm{J}=1.4 \mathrm{~Hz}, 2.3 \mathrm{~Hz}, 1 \mathrm{H}) .{ }^{13} \mathrm{C}-\mathrm{NMR}\left(75 \mathrm{MHz}, \mathrm{CDCl}_{3}\right): \delta=14.0,14.6$, 38.8, 64.3, 67.7, 68.2, 69.9, 91.2. IR (film): $\tilde{v}=3440$ (br, s), 2987 (w), 2359 (w), 2090 (w), 1653 (m), 1558 (w), 1539 (w), 1506 (w), 1387 (w), 1115 (m), 1062 (m), 979 (w), 949 (w). HRMS (ESI): $m / z$ calcd. for $\mathrm{C}_{8} \mathrm{H}_{14} \mathrm{NaO}_{4}\left(\mathrm{M}+\mathrm{Na}^{+}\right)$: 197.0784 , found 197.0789.

\section{(1R,2S,6S)-1-((S)-1-(benzyloxy)ethyl)-4-methoxy-2-methyl-3,7-dioxabicyclo}

\section{[4.1.0]heptane (17)}

Epoxide 16 ( $\alpha$-anomer, $0.17 \mathrm{~g}, 0.90 \mathrm{mmol}$ ) was dissolved in a mixture of THF/DMF 1:1 $(10 \mathrm{~mL})$ and cooled to $0{ }^{\circ} \mathrm{C}$. $\mathrm{NaH}(0.08 \mathrm{~g}, 1.99 \mathrm{mmol})$ was added and stirred for $10 \mathrm{~min}$ at this 
temperature. $\mathrm{BnBr}(0.23 \mathrm{~mL}, 1.90 \mathrm{mmol})$ was added dropwise to the red solution. The reaction mixture was stirred for $30 \mathrm{~min}$ at $0{ }^{\circ} \mathrm{C}$, then warmed to room temperature and stirred for another $30 \mathrm{~min}$. Water $(20 \mathrm{~mL})$ was added carefully and the aqueous phase was extracted with ethyl acetate $(5 \times 20 \mathrm{~mL})$. The combined organic layers were dried with $\mathrm{Na}_{2} \mathrm{SO}_{4}$, the solvent was removed. Toluene $(3 \times 30 \mathrm{~mL})$ was added and removed in vacuum to remove traces of DMF. The residue was purified by flash chromatography $(20 \mathrm{~g}$ silica gel, pentane/ $\left.\mathrm{Et}_{2} \mathrm{O} 2: 1\right)$ to afford Bn-protected epoxide 17 as a colourless oil $(0.24 \mathrm{~g}, 0.87 \mathrm{mmol}$, $97 \%) . \mathrm{R}_{\mathrm{f}}=0.6\left(\mathrm{P} \mathrm{Et}_{2} \mathrm{O} 1: 1\right) .[\alpha]_{\mathrm{D}}=-120.82\left(\mathrm{c}=1.1, \mathrm{CHCl}_{3}\right) .{ }^{1} \mathrm{H}-\mathrm{NMR}\left(300 \mathrm{MHz}, \mathrm{CDCl}_{3}\right)$ : $\delta=1.21(\mathrm{~d}, \mathrm{~J}=6.6 \mathrm{~Hz}, 3 \mathrm{H}), 1.26(\mathrm{~d}, \mathrm{~J}=6.6 \mathrm{~Hz}, 3 \mathrm{H}), 1.85(\mathrm{ddd}, \mathrm{J}=2.5 \mathrm{~Hz}, 4.72 \mathrm{~Hz}, 15.4 \mathrm{~Hz}$, 1H), $2.08(\mathrm{dd}, \mathrm{J}=4.6 \mathrm{~Hz}, 15.4 \mathrm{~Hz}, 1 \mathrm{H}), 3.28(\mathrm{~d}, \mathrm{~J}=4.3 \mathrm{~Hz}, 1 \mathrm{H}), 3.29$ (s, 3H), 3.44 (q, J = $6.5 \mathrm{~Hz}, 1 \mathrm{H}), 4.15(\mathrm{q}, \mathrm{J}=6.5 \mathrm{~Hz}, 1 \mathrm{H}), 4.41$ (d, J = 11.7 Hz, 1H), 4.52 (dd, J = 2.5 Hz, $4.5 \mathrm{~Hz}$, $1 \mathrm{H}), 4.64(\mathrm{~d}, \mathrm{~J}=11.7 \mathrm{~Hz}, 1 \mathrm{H}), 7.19-7.28(\mathrm{~m}, 5 \mathrm{H}) .{ }^{13} \mathrm{C}-\mathrm{NMR}\left(75 \mathrm{MHz}, \mathrm{CDCl}_{3}\right): \delta=16.5$, 17.9, 29.6, 53.9, 55.1, 60.9, 62.6, 72.2, 73.6, 94.9, 127.5, 127.6, 128.3, 138.5. IR (film): $\tilde{v}=$ 2982 (m), 2936 (m), 2833 (w), 1454 (m), 1375 (m), 1336 (w), 1237 (w), 1201 (w), 1133 (s), 1101 (s), 1061 (s), 1006 (m), 885 (w), 738 (m), 699 (m). HRMS (ESI): m/z calcd. for $\mathrm{C}_{16} \mathrm{H}_{22} \mathrm{NaO}_{4}\left(\mathrm{M}+\mathrm{Na}^{+}\right): 301.1410$, found 301.1411.

\section{$(2 S, 3 R, 4 R)-4$-allyloxy-3-((S)1-benzyloxy-ethyl)-6-methoxy-2-methyl-tetrahydro-pyran-}

\section{3-ol (18)}

Bn-protected epoxide $17(0.22 \mathrm{~g}, 0.80 \mathrm{mmol})$ was dissolved in allyl alcohol $(10 \mathrm{~mL})$ and cooled to $0{ }^{\circ} \mathrm{C}$. $\mathrm{HClO}_{4}(70 \%$ in water, $0.12 \mathrm{~mL}, 2.00 \mathrm{mmol})$ was added slowly and stirred at $0{ }^{\circ} \mathrm{C}$ for $2 \mathrm{~h}$, then at room temperature for $5 \mathrm{~h}$. The yellow solution was diluted with $\mathrm{CH}_{2} \mathrm{Cl}_{2}$ $(20 \mathrm{~mL})$ and sat. $\mathrm{NaHCO}_{3}$-solution $(20 \mathrm{~mL})$ was added. The aqueous solution was extracted with $\mathrm{CH}_{2} \mathrm{Cl}_{2}(4 \times 20 \mathrm{~mL})$. The combined organic phases were dried with $\mathrm{Na}_{2} \mathrm{SO}_{4}$ and the solvent was removed in vacuo. The residue was dissolved in $\mathrm{MeOH}(10 \mathrm{~mL})$ and CSA $(0.04 \mathrm{~g}, 0.16 \mathrm{mmol})$ was added and stirred over night at room temperature. The solution was diluted with ethyl acetate $(20 \mathrm{~mL})$, sat. $\mathrm{NaHCO}_{3}$-solution $(20 \mathrm{~mL})$ was added and $\mathrm{MeOH}$ was removed in vacuo. The aqueous phase was extracted with ethyl acetate (4 x $20 \mathrm{~mL}$ ). The combined organic phases were dried with $\mathrm{Na}_{2} \mathrm{SO}_{4}$ and the solvent was removed in vacuo. The residue was purified by flash chromatography (20 g silica gel, pentane/ $\left.\mathrm{Et}_{2} \mathrm{O} 3: 1\right)$ to afford allyl ether 18 as a bright yellow colourless oil $(0.20 \mathrm{~g}, 0.60 \mathrm{mmol}, 76 \%$, anomeric mixture eq:ax 3:1 revealed by $\left.{ }^{1} \mathrm{H}-\mathrm{NMR}\right)$. Major product, $\beta$-glycoside: $\mathrm{R}_{\mathrm{f}}=0.43\left(\mathrm{P}: \mathrm{Et}_{2} \mathrm{O} 1: 1\right) .[\alpha]_{\mathrm{D}}=-$ 
$78.27\left(\mathrm{c}=1.1, \mathrm{CHCl}_{3}\right) .{ }^{1} \mathrm{H}-\mathrm{NMR}\left(300 \mathrm{MHz}, \mathrm{CDCl}_{3}\right): \delta=1.14(\mathrm{~d}, \mathrm{~J}=6.4 \mathrm{~Hz}, 3 \mathrm{H}), 1.20(\mathrm{~d}, \mathrm{~J}=$ $6.6 \mathrm{~Hz}, 3 \mathrm{H}), 1.73$ (ddd, J = 2.8 Hz, $9.9 \mathrm{~Hz}, 13.9 \mathrm{~Hz}, 1 \mathrm{H}), 1.9$ (dpt, J = 2.7 Hz, $14.1 \mathrm{~Hz}, 1 \mathrm{H}$ ), $3.36(\mathrm{pt}, \mathrm{J}=2.3 \mathrm{~Hz}, 1 \mathrm{H}), 3.42(\mathrm{~s}, 3 \mathrm{H}), 3.53(\mathrm{q}, \mathrm{J}=6.5 \mathrm{~Hz}, 1 \mathrm{H}), 3.78(\mathrm{pt}, \mathrm{J}=2.9 \mathrm{~Hz}, 1 \mathrm{H}), 3.87$ (ddpt, J = 1.5, 5.4, $12.7 \mathrm{~Hz}, 1 \mathrm{H}), 3.92(\mathrm{q}, \mathrm{J}=6.5 \mathrm{~Hz}, 1 \mathrm{H}), 4.04$ (ddpt, J = 1.5, 5.5, $12.6 \mathrm{~Hz}$, $1 \mathrm{H}), 4.46(\mathrm{~d}, \mathrm{~J}=11.7 \mathrm{~Hz}, 1 \mathrm{H}), 4.59(\mathrm{dd}, \mathrm{J}=2.4,9.7 \mathrm{~Hz}, 1 \mathrm{H}), 4.60(\mathrm{~d}, \mathrm{~J}=11.5 \mathrm{~Hz}, 1 \mathrm{H}), 5.07$ (ddd, J = 1.4, 3.1, 10.4 Hz, 1H), 5.19 (ddd, J = 1.7 Hz, 3.4 Hz, 17.3 Hz), 5.85 (m, $1 \mathrm{H}), 7.19$ $7.30(\mathrm{~m}, 5 \mathrm{H}) .{ }^{13} \mathrm{C}-\mathrm{NMR}\left(75 \mathrm{MHz}, \mathrm{CDCl}_{3}\right): \delta=14.6,14.7,31.1,56.2,69.9,71.3,71.4,73.3$, 76.9, 78.0, 99.5, 116.4, 127.4, 127.7, 128.3, 134.8, 138.7. IR (film): $\tilde{v}=3365$ (m), $3064(\mathrm{w})$, 2982 (s), 2939 (s), 1722 (w), 1453 (s), 1379 (s), 1303 (m), 1270 (m), 1206 (m), 1056 (s), 993 (s), 942 (w), 738 (m), 699 (m). HRMS (ESI): $m / z$ calcd. for $\mathrm{C}_{19} \mathrm{H}_{28} \mathrm{NaO}_{5}\left(\mathrm{M}+\mathrm{Na}^{+}\right): 359.1829$, found 359.1834 .

\section{(2S)-3-((S)-1-hydroxyethyl)-6-methoxy-2-methyltetrahydro-2H-pyran-3,4-diol (19 + 20)}

Allylether $18(0.15 \mathrm{~g}, 0.44 \mathrm{mmol})$ was dissolved in $\mathrm{MeOH} / \mathrm{CH}_{2} \mathrm{Cl}_{2} 3: 2(5 \mathrm{~mL})$ and $\mathrm{PdCl}_{2}$ $(0.09 \mathrm{~g}, 0.52 \mathrm{mmol})$ was added. The dark brown suspension was stirred at room temperature for $2 \mathrm{~h}$. The mixture was filtered over a pad of celite and $\mathrm{NaCl}$-solution $(5 \mathrm{M}, 30 \mathrm{~mL})$ was added. The aqueous phase was extracted with $\mathrm{CH}_{2} \mathrm{Cl}_{2}(4 \times 10 \mathrm{~mL})$ The combined organic phases were dried with $\mathrm{Na}_{2} \mathrm{SO}_{4}$ and the solvent was removed in vacuo. The residue was dissolved in $\mathrm{MeOH}(5 \mathrm{~mL})$ and $\mathrm{Pd} / \mathrm{C}(0.05 \mathrm{~g})$ was added. The suspension was stirred over night under hydrogen atmosphere at room temperature. The mixture was filtered over a pad of celite and the solvent was removed in vacuo. The residue was purified by flash chromatography (10 g silica gel, $\left.\mathrm{CH}_{2} \mathrm{Cl}_{2} / \mathrm{MeOH} 100: 2\right)$ to yield the $\alpha$-methylglycoside 20 (56 mg, $0.27 \mathrm{mmol}, 62 \%$ ) and the $\beta$-methyl glycoside 19 (14 mg, $0.07 \mathrm{mmol}, 16 \%$ ) both as colourless oils. Higher Rf compound, $\alpha$-anomer 20: $\mathrm{R}_{\mathrm{f}}=0.44\left(\mathrm{CH}_{2} \mathrm{Cl}_{2} / \mathrm{MeOH} 10: 1\right) .[\alpha]_{\mathrm{D}}=-$ $102.2\left(\mathrm{c}=0.64, \mathrm{CHCl}_{3}\right) .{ }^{1} \mathrm{H}-\mathrm{NMR}\left(300 \mathrm{MHz}, \mathrm{CDCl}_{3}\right): \delta=1.27(\mathrm{~d}, \mathrm{~J}=6.6 \mathrm{~Hz}, 3 \mathrm{H}), 1.31(\mathrm{~d}, \mathrm{~J}$ $=6.6 \mathrm{~Hz}, 3 \mathrm{H}), 1.85(\mathrm{dd}, \mathrm{J}=1.8 \mathrm{~Hz}, 14.8 \mathrm{~Hz}, 1 \mathrm{H}), 2.21(\mathrm{dpt}, \mathrm{J}=3.73 \mathrm{~Hz}, 14.2 \mathrm{~Hz}, 1 \mathrm{H}), 2.41$ (bs, $1 \mathrm{H}) \quad 3.38(\mathrm{~s}, 3 \mathrm{H}), 3.54(\mathrm{~d}, \mathrm{~J}=9.4 \mathrm{~Hz}, 1 \mathrm{H}), 3.81(\mathrm{dd}, \mathrm{J}=2.8,3.0 \mathrm{~Hz}, 1 \mathrm{H}), 3.87(\mathrm{q}, \mathrm{J}=6.5$ $\mathrm{Hz}, 1 \mathrm{H}), 4.20(\mathrm{q}, \mathrm{J}=6.4 \mathrm{~Hz}, 1 \mathrm{H}), 4.81(\mathrm{~d}, \mathrm{~J}=3.4 \mathrm{~Hz}, 1 \mathrm{H}) \cdot{ }^{13} \mathrm{C}-\mathrm{NMR}\left(75 \mathrm{MHz}, \mathrm{CDCl}_{3}\right): \delta=$ 15.4, 18.1, 32.1, 55.2, 64.4, 69.4, 70,4 72.5, 98.6. IR (film): $\tilde{v}=3448$ (br, s), 2940 (s), 2836 (s), 2359 (w), 2343 (w), 1717 (w), 1653 (w), 1448 (m), 1370 (m), 1313 (m), 1190 (m), 1127 (s), 1095 (s), 1046 (s), 998 (s), 895 (w), 826 (w), 786 (w), 736 (w), 668 (w). HRMS (ESI): $m / z$ calcd. for $\mathrm{C}_{9} \mathrm{H}_{18} \mathrm{NaO}_{5}\left(\mathrm{M}+\mathrm{Na}^{+}\right)$: 229.1046, found 229.1049. Lower Rf compound, $\beta$ anomer 19: $\mathrm{R}_{\mathrm{f}}=0.4\left(\mathrm{Et}_{2} \mathrm{O}\right)$. $[\alpha]_{\mathrm{D}}=10.50\left(\mathrm{c}=0.20, \mathrm{CHCl}_{3}\right) .{ }^{1} \mathrm{H}-\mathrm{NMR}\left(300 \mathrm{MHz}, \mathrm{CDCl}_{3}\right): \delta=$ $1.27(\mathrm{~d}, \mathrm{~J}=6.6 \mathrm{~Hz}, 3 \mathrm{H}), 1.30(\mathrm{~d}, \mathrm{~J}=6.6 \mathrm{~Hz}, 3 \mathrm{H}), 1.82(\mathrm{dpt}, \mathrm{J}=3.0 \mathrm{~Hz}, 14.2 \mathrm{~Hz}, 1 \mathrm{H}), 1.92$ 
(ddd, J = 3.2 Hz, 9.5 Hz, 14.3 Hz, 1H), 3.51 (s, 3H), 3.89 (q, J = 6.7 Hz, 1H), 4.08 (q, J = 6.5 $\mathrm{Hz}, 1 \mathrm{H}), 4.13(\mathrm{pt}, \mathrm{J}=3.0 \mathrm{~Hz}, 1 \mathrm{H}), 4.71(\mathrm{dd}, \mathrm{J}=2.9 \mathrm{~Hz}, 9.5 \mathrm{~Hz}, 1 \mathrm{H}) .{ }^{13} \mathrm{C}-\mathrm{NMR}(75 \mathrm{MHz}$, $\mathrm{CDCl}_{3}$ ): $\delta=15.2,18.3,36.4,56.4,70.5,70.7,70.9,72.7,99.5$. IR (film): $\tilde{v}=3442$ (br, s), 2939 (s), 2360 (w), 2343 (w), 1654 (w), 1438 (m), 1395 (m), 1281 (w), 1160 (m), 1121 (s), 1058 (s), 1007 (s), 914 (w), 885 (w), 723 (m), 695 (m). HRMS (ESI): m/z calcd. for $\mathrm{C}_{9} \mathrm{H}_{18} \mathrm{NaO}_{5}\left(\mathrm{M}+\mathrm{Na}^{+}\right): 229.1046$, found 229.1054 .

(1S)-1-((2S,6S)-4-(3,5-dinitrobenzoyloxy)-3-hydroxy-6-methoxy-2-methyltetrahydro-2Hpyran-3-yl)ethyl 3,5-dinitrobenzoate (21)<smiles>CO[C@H]1C[C@H](OC(=O)c2cc([N+](=O)[O-])cc([N+](=O)[O-])c2)[C@](C)(C(C)OC(=O)c2cc([N+](=O)[O-])cc([N+](=O)[O-])c2)[C@H](C)O1</smiles>

$\beta$-Methyl glycoside $19(2.0 \mathrm{mg}, 9.7 \mu \mathrm{mol})$ was dissolved in pyridine $(1.5 \mathrm{~mL})$ and 3,5 dinitrobenzoyl chloride (31 mg, $0.146 \mathrm{mmol}$ ) was added. The yellow solution was stirred for 16 h. Sat. $\mathrm{NH}_{4} \mathrm{Cl}$-solution $(10 \mathrm{~mL})$ was added and the aqueous layer was extracted with $\mathrm{CH}_{2} \mathrm{Cl}_{2}$ (4 x $10 \mathrm{~mL}$ ). The combined organic layers were dried with $\mathrm{Na}_{2} \mathrm{SO}_{4}$ and the solvent was removed in vacuo. The residue was purified by flash chromatography (3 g silica gel, pentane/ $\mathrm{Et}_{2} \mathrm{O}$ 1:1) to afford the bis-(dinitrobenzoyl) ester 21 as a white solid (4.6 mg, $7.7 \mu \mathrm{mol}, 80 \%) . \mathrm{R}_{\mathrm{f}}=0.7\left(\mathrm{Et}_{2} \mathrm{O}\right) . \quad[\alpha]_{\mathrm{D}}=-149.00\left(0.30, \mathrm{CHCl}_{3}\right) .{ }^{1} \mathrm{H}-\mathrm{NMR}\left(300 \mathrm{MHz}, \mathrm{CDCl}_{3}\right): \delta$ $=1.36(\mathrm{~d}, \mathrm{~J}=7.0 \mathrm{~Hz}, 3 \mathrm{H}), 1.43(\mathrm{~d}, \mathrm{~J}=6.2 \mathrm{~Hz}, 3 \mathrm{H}), 2.06(\mathrm{dpt}, \mathrm{J}=2.8 \mathrm{~Hz}, 15.1 \mathrm{~Hz}, 1 \mathrm{H}), 2.16$ (ddd, J = 3.4 Hz, 9.6 Hz, 15.0 Hz, 1H), 2.92 (bs, 1H), 3.56 (s, 3H), 4.28 (q, J = 6.3 Hz, 1H), 4.77 (dd, J = 2.6 Hz, 9.4 Hz, 1H), 5.19 (q, J = 6.9 Hz, 1H), 5.91 (pt, J = 2.9 Hz, 1H), 9.18 (d, J $=2.1 \mathrm{~Hz}, 2 \mathrm{H}), 9.19(\mathrm{~d}, \mathrm{~J}=2.1 \mathrm{~Hz}, 2 \mathrm{H}), 9.26(\mathrm{~d}, \mathrm{~J}=2.1 \mathrm{~Hz}, 1 \mathrm{H}), 9.29(\mathrm{~d}, \mathrm{~J}=2.1 \mathrm{~Hz}, 1 \mathrm{H})$.

${ }^{13} \mathrm{C}-\mathrm{NMR}\left(75 \mathrm{MHz}, \mathrm{CDCl}_{3}\right): \delta=14.4,16.2,33.3,56.7,70.9,72.1,73.3,75.4,99.5,122.7$, 123.0, 129.3, 129.6, 133.1, 133.5, 148.8, 149.0, 161.0, 161.8. HRMS (ESI): $m / z$ calcd. for $\mathrm{C}_{23} \mathrm{H}_{22} \mathrm{~N}_{4} \mathrm{O}_{15}\left(\mathrm{M}+\mathrm{Cl}^{-}\right)$: 629.0776, found 629.0787.

Supplementary crystallographic data of $\mathbf{2 1}$ with further details has been deposited in the Cambridge Cristallographic data Centre and allocated deposition number CCDC 658267. These data can be obtained free of charge via www.ccdc.cam.uk. or by contacting The 
Cambridge Crystallographic data Centre, 12, Union Roas, Cambridge CB2 1EZ, UK; fax: +44 1223336033.

Dr. Klaus Harms

Chemistry Department

University of Marburg

Table 1. Crystal data and structure refinement for 21.

Crystal data

Identification code

Habitus, colour

Crystal size

Crystal system

Space group

Unit cell dimensions

\section{Volume}

Cell determination

Empirical formula

Formula weight

Density (calculated)

Absorption coefficient

$\mathrm{F}(000)$

Data collection:

Diffractometer type

Wavelength

Temperature

Theta range for data collection

Index ranges

Data collection software

Cell refinement software

Data reduction software

Solution and refinement:

Reflections collected

Independent reflections

Completeness to theta $=24.98^{\circ}$

Observed reflections

Reflections used for refinement

Extinction coefficient

Absorption correction

Max. and min. transmission

Flack parameter (absolute struct.)

Largest diff. peak and hole

Solution

Refinement

Treatment of hydrogen atoms

Programs used

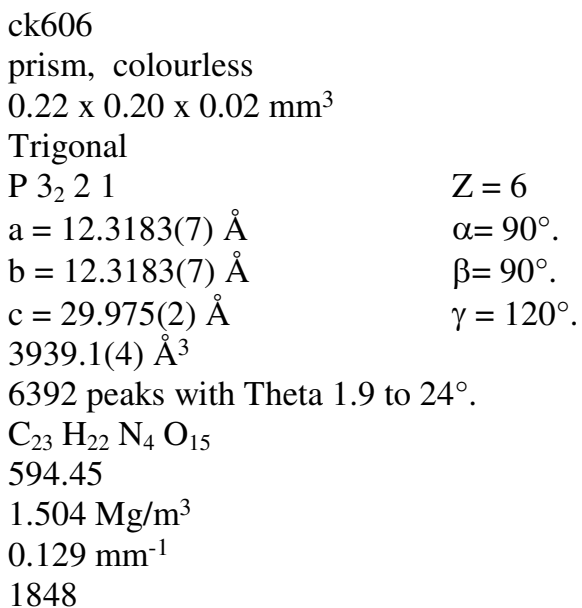

IPDS2

$0.71073 \AA$

153(2) K

1.91 to $24.98^{\circ}$.

$-9<=\mathrm{h}<=14,-14<=\mathrm{k}<=11,-33<=\mathrm{l}<=35$

STOE WinXpose (X-Area)

STOE WinCell (X-Area)

STOE WinIntegrate (X-Area)

11756

$2660[\mathrm{R}(\mathrm{int})=0.0799]$

$99.9 \%$

$1558[\mathrm{I}>2 \operatorname{sigma}(\mathrm{I})]$

2660

$X=0.00161(16)$

Semi-empirical from equivalents

1.0006 and 0.9572

$-2.2(15)$

0.154 and -0.153 e. $\AA^{-3}$

Direct methods

Full-matrix least-squares on $\mathrm{F}^{2}$

$\mathrm{CH}$ geom, constr., $\mathrm{OH}$ difmap, ref

SIR2004 (Giacovazzo et al, 2004)

SHELXL-97 (Sheldrick, 1997)

Diamond 3.1, STOE IPDS2 software 
Data / restraints / parameters

Goodness-of-fit on $\mathrm{F}^{2}$

$\mathrm{R}$ index (all data)

$\mathrm{R}$ index conventional [I $>2 \operatorname{sigma}(\mathrm{I})]$
2660 / 0 / 387

0.874

$\mathrm{wR} 2=0.0595$

$\mathrm{R} 1=0.0379$ 


\section{Comparison of ${ }^{1} \mathrm{H}$-NMR-shifts of natural and synthetic}

methyl 7-dihydro-trioxacarcinoside B

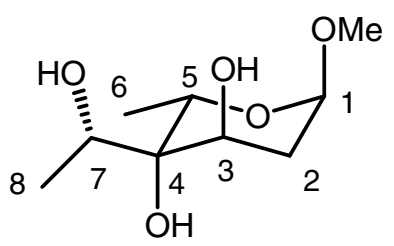

\begin{tabular}{|c|c|c|}
\hline Position & $\begin{array}{c}\text { Matern et al. }{ }^{[1]} \\
\left(100 \mathrm{MHz}_{\mathrm{CDCl}}\right) \delta / \mathrm{ppm}\end{array}$ & $\begin{array}{c}\text { Koert et al. } \\
\left(300 \mathrm{MHz}, \mathrm{CDCl}_{3}\right) \delta / \mathrm{ppm}\end{array}$ \\
\hline $\mathrm{H}-5$ & 1.27 & 1.27 \\
\hline $\mathrm{H}-8$ & 1.31 & 1.31 \\
\hline $\mathrm{H}-2 \mathrm{a}$ & 1.83 & 2.85 \\
\hline $\mathrm{H}-2 \mathrm{e}$ & 2.22 & 3.54 \\
\hline $\mathrm{CH}_{3}-\mathrm{O}$ & 3.54 & 3.87 \\
\hline $\mathrm{H}-3 \mathrm{e}$ & 3.80 & 3.82 \\
\hline $\mathrm{H}-7$ & 3.84 & 4.20 \\
\hline $\mathrm{H}-5 \mathrm{e}$ & 4.19 & 4.81 \\
\hline $\mathrm{H}-1$ & 4.80 & \\
\hline
\end{tabular}

[1] U.Matern, H. Grisebach, Eur. J. Biochem. 1972, 29, 5 


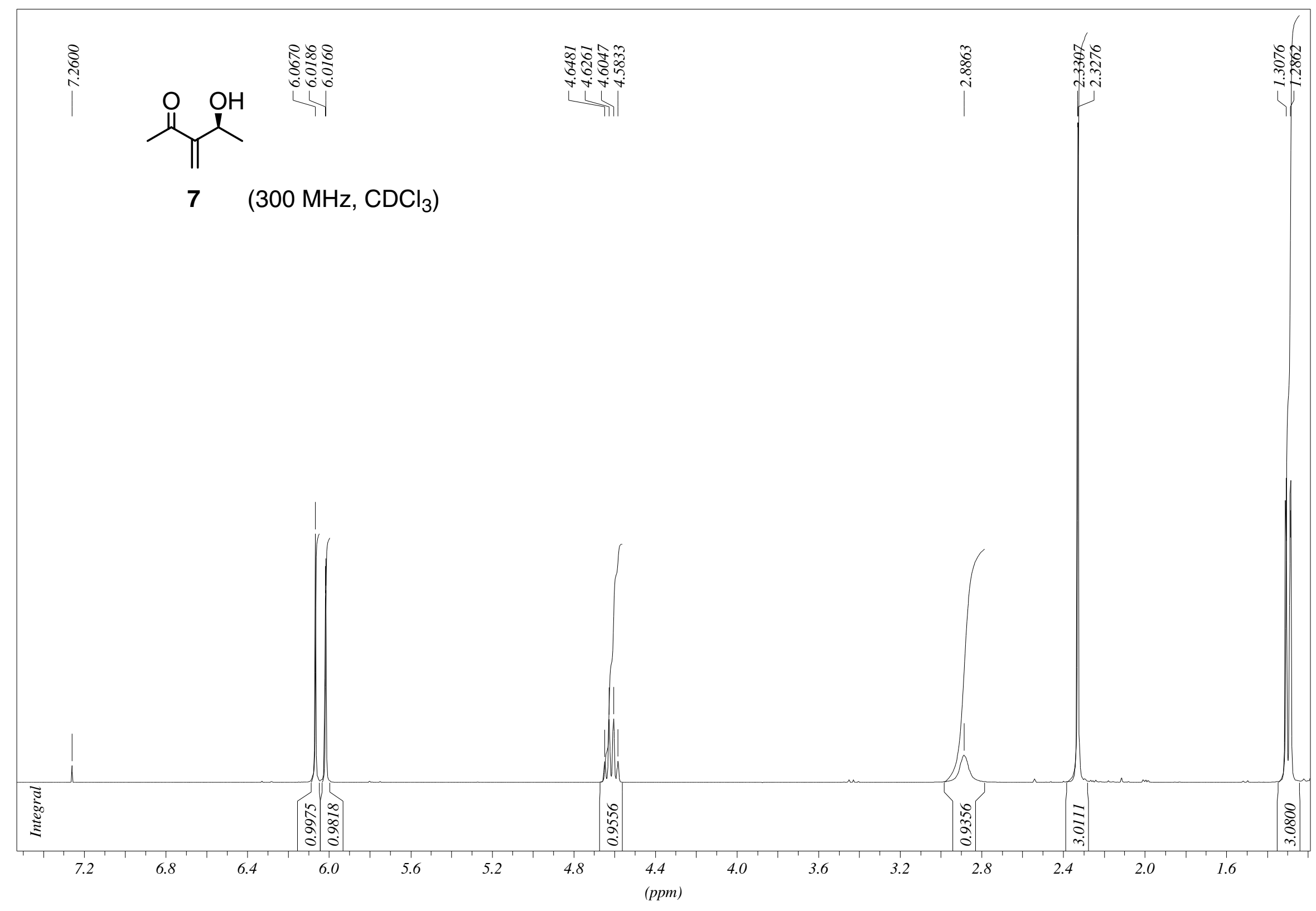




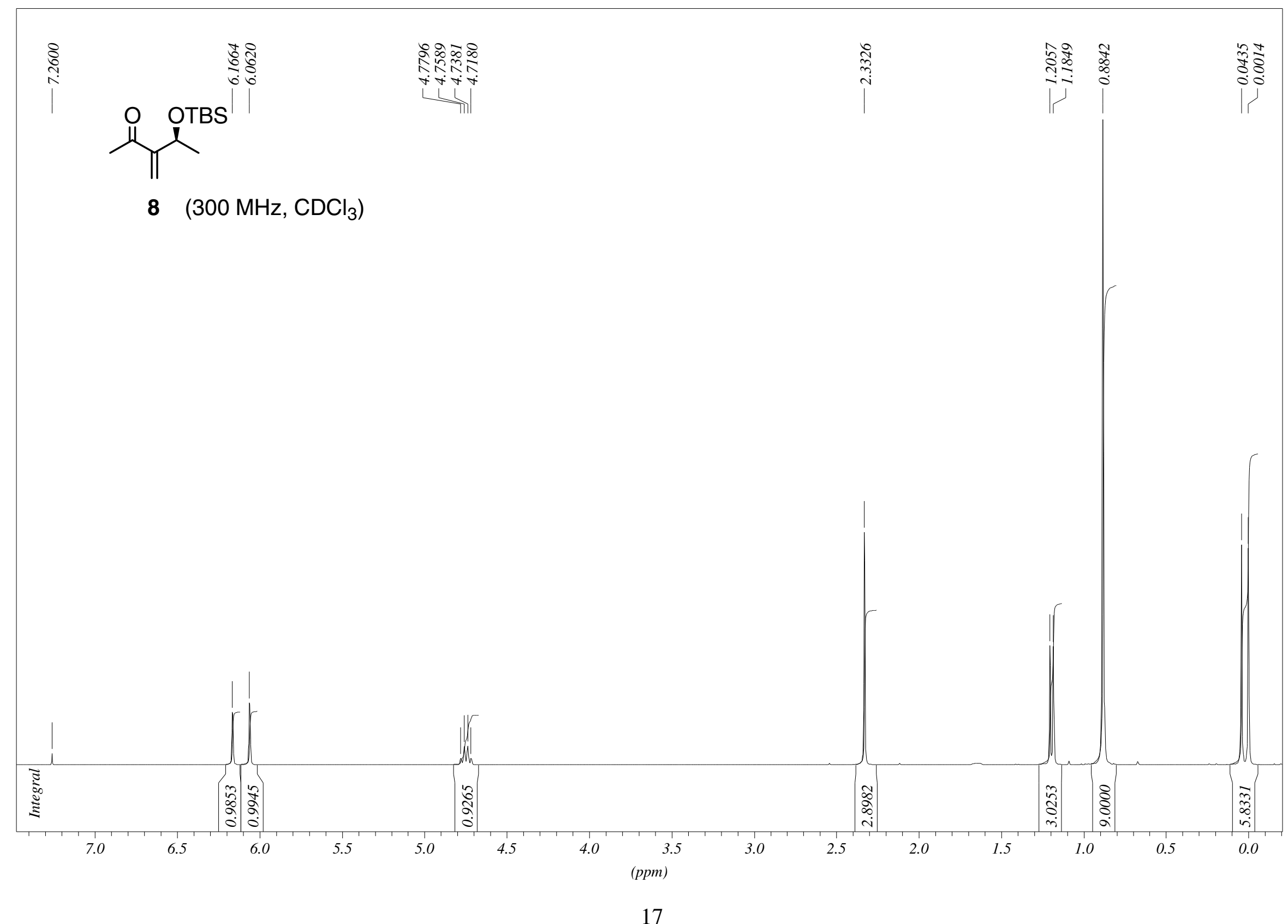




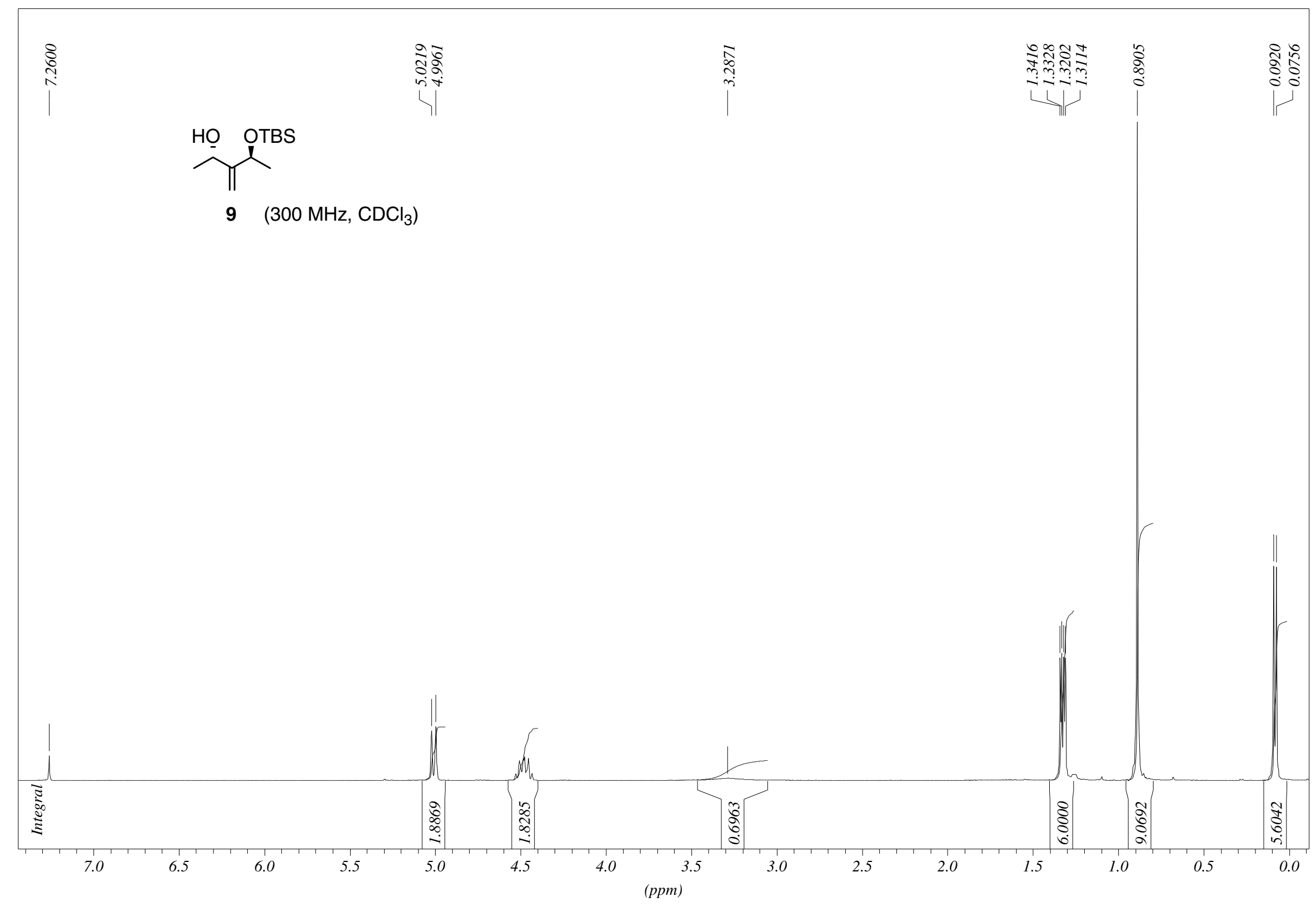




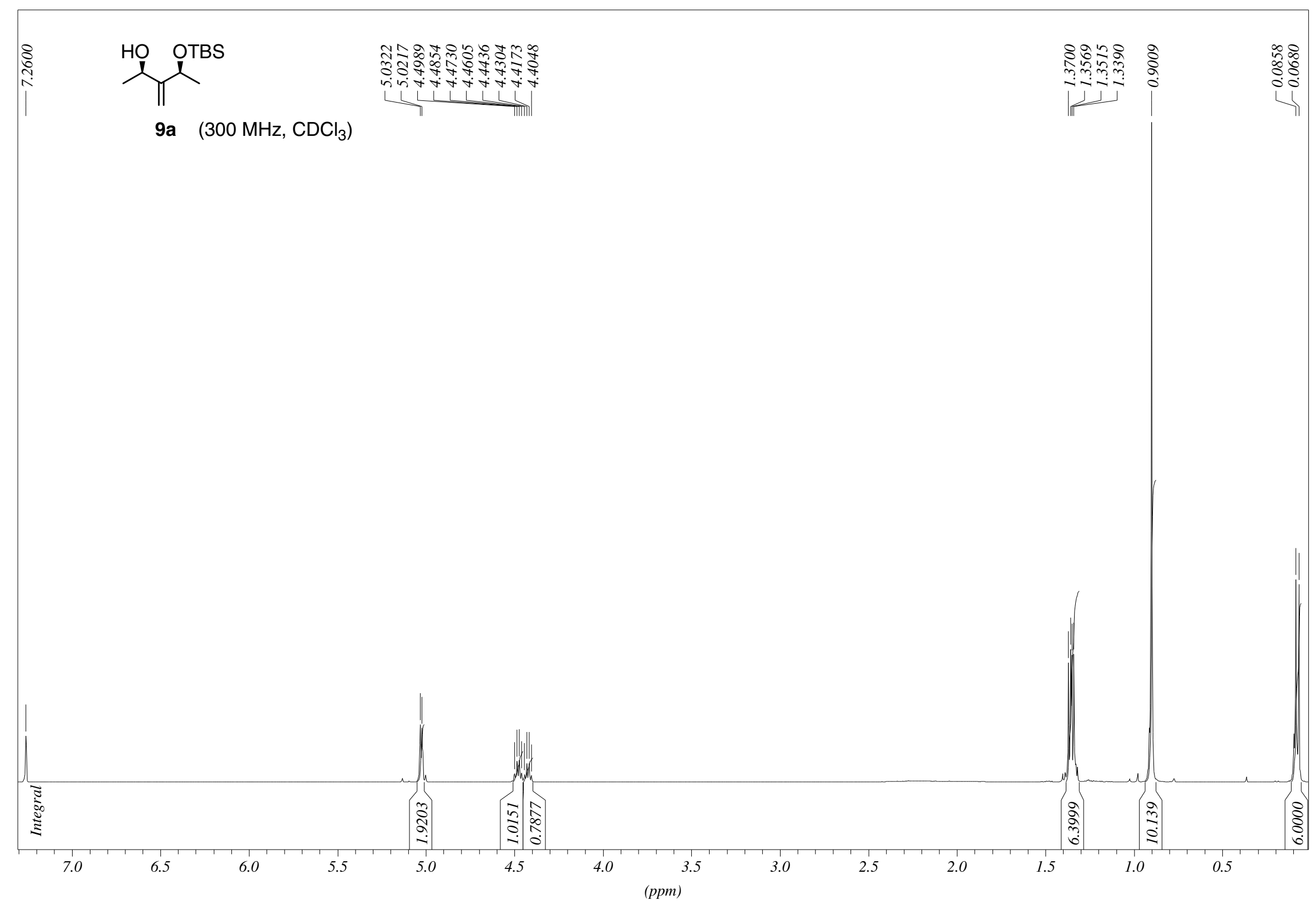




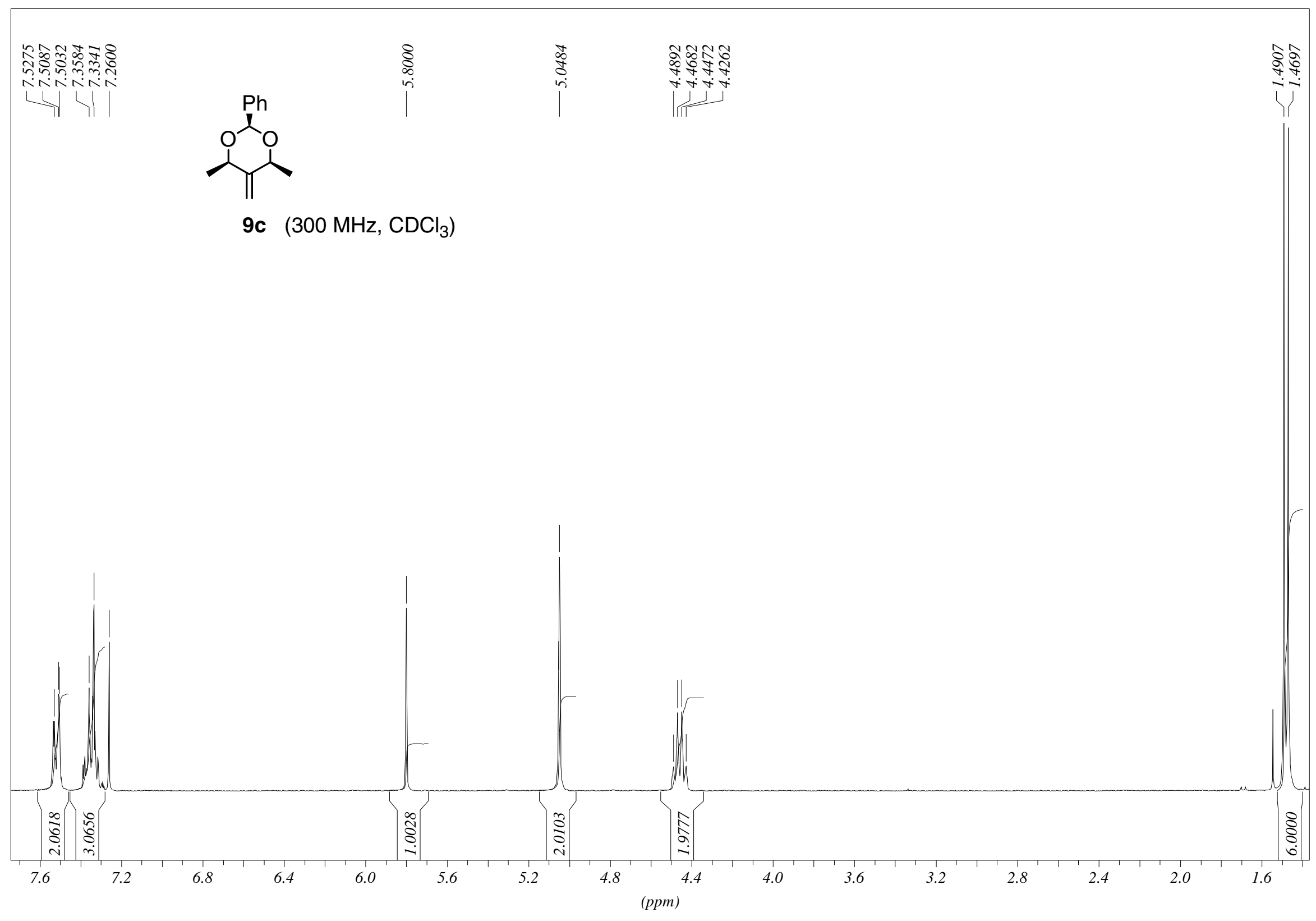

20 


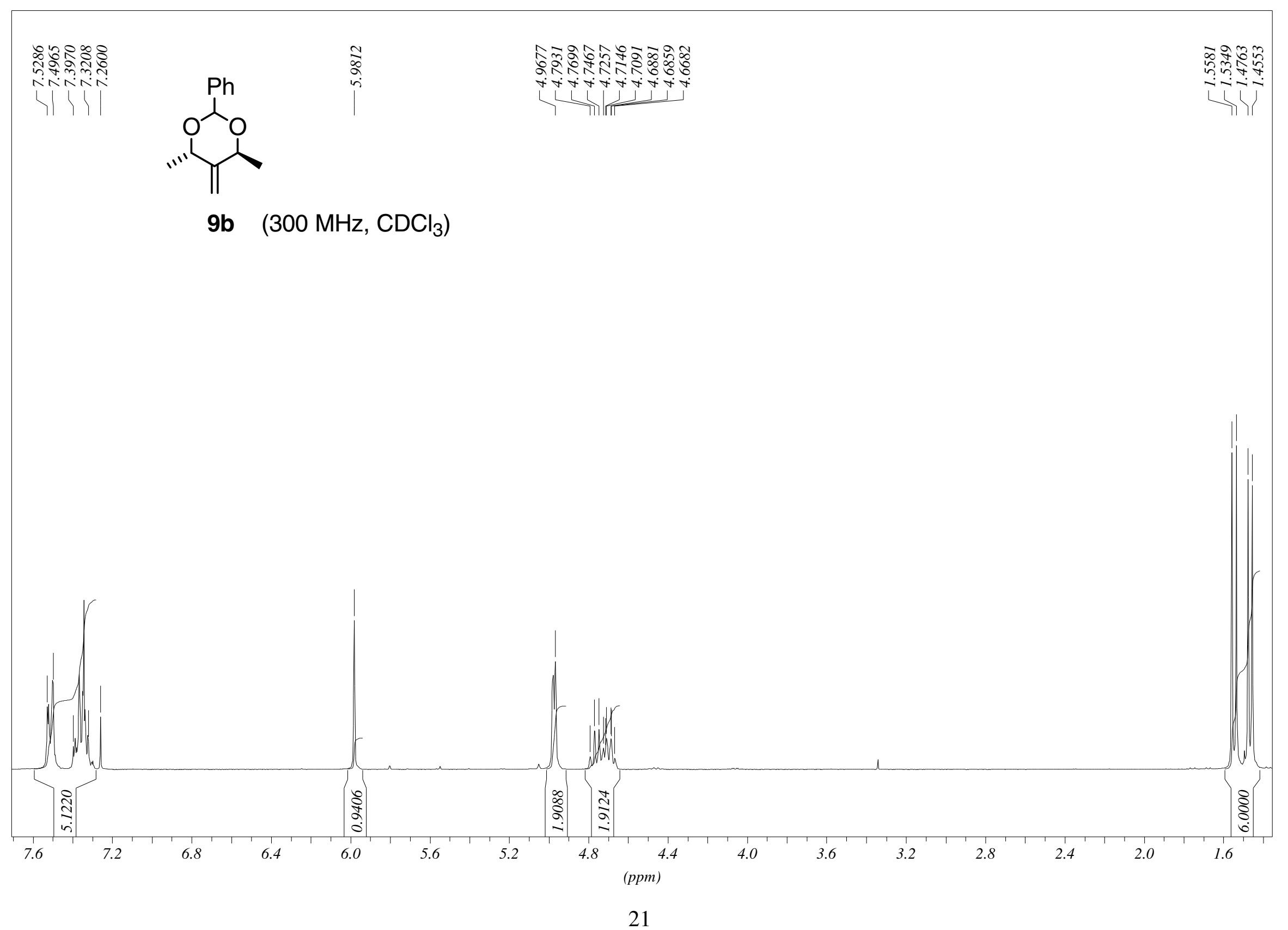




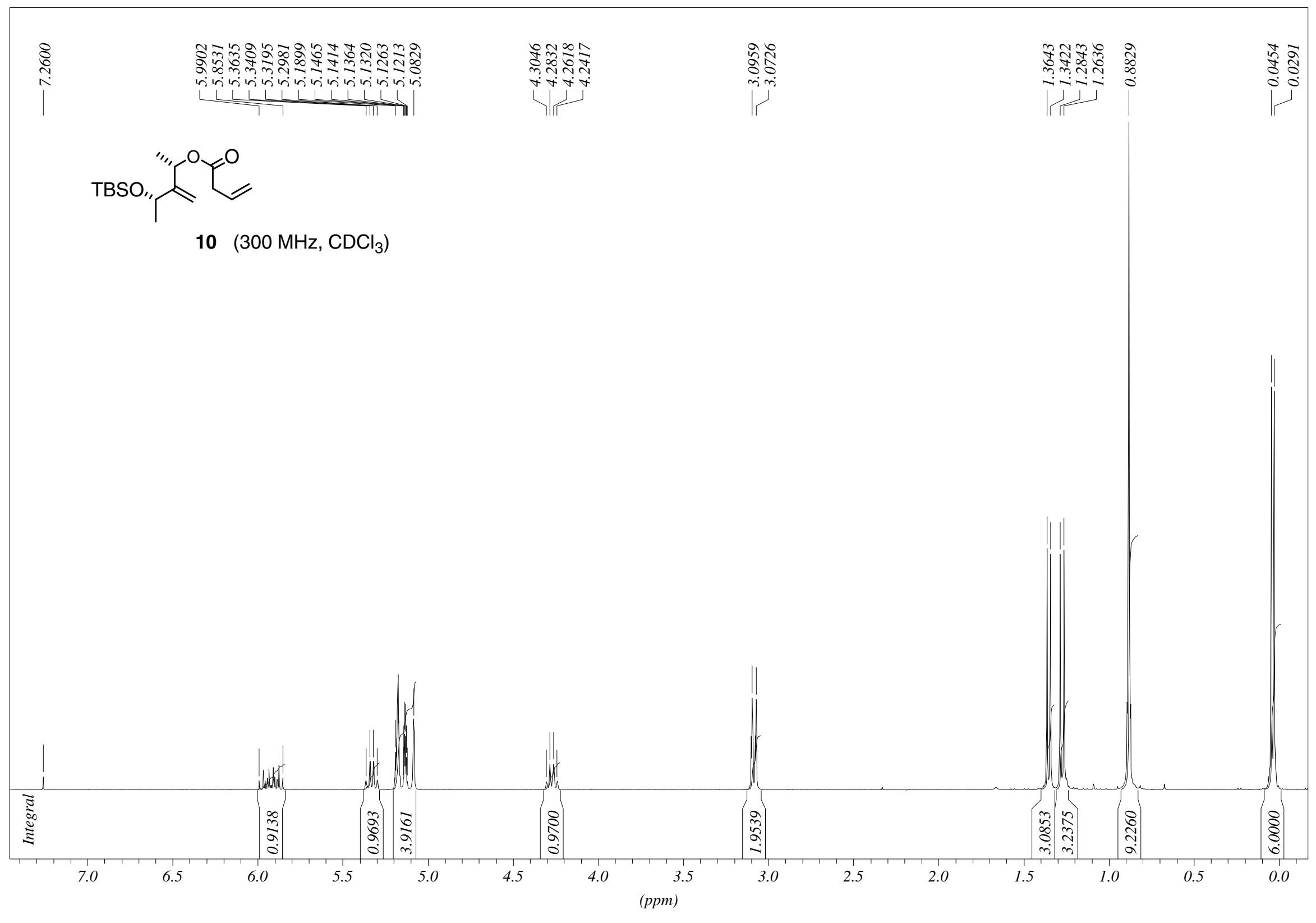




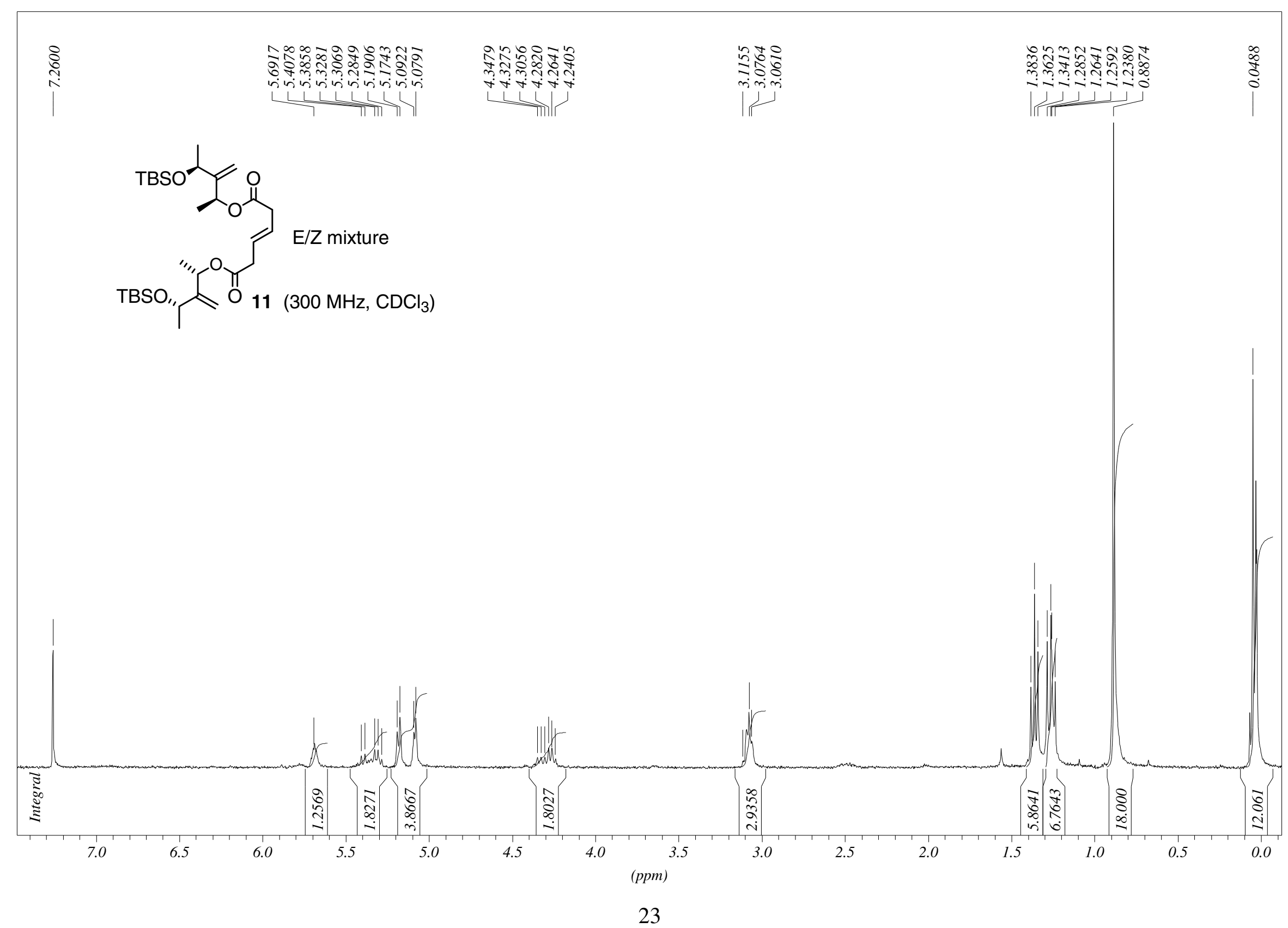




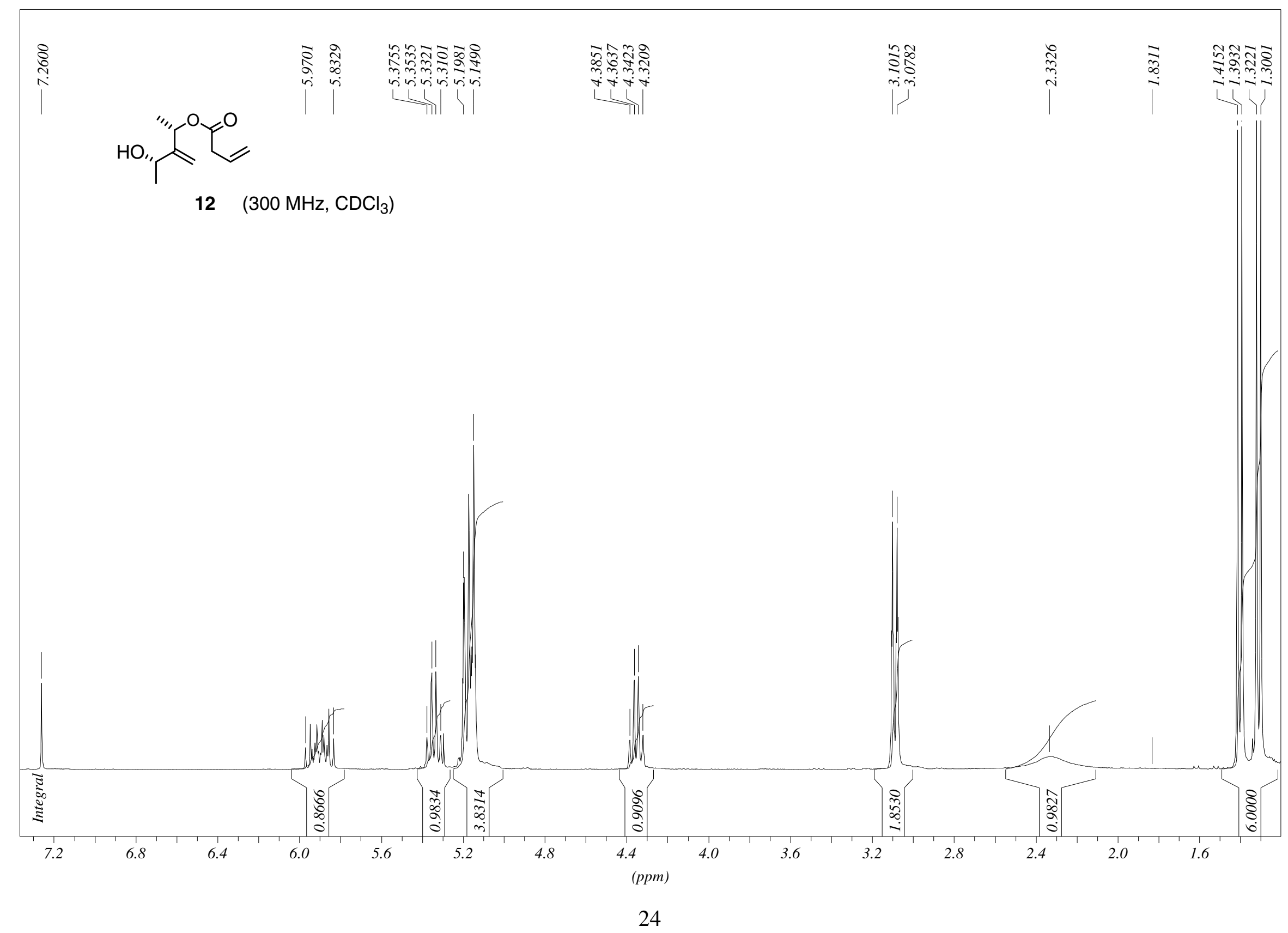




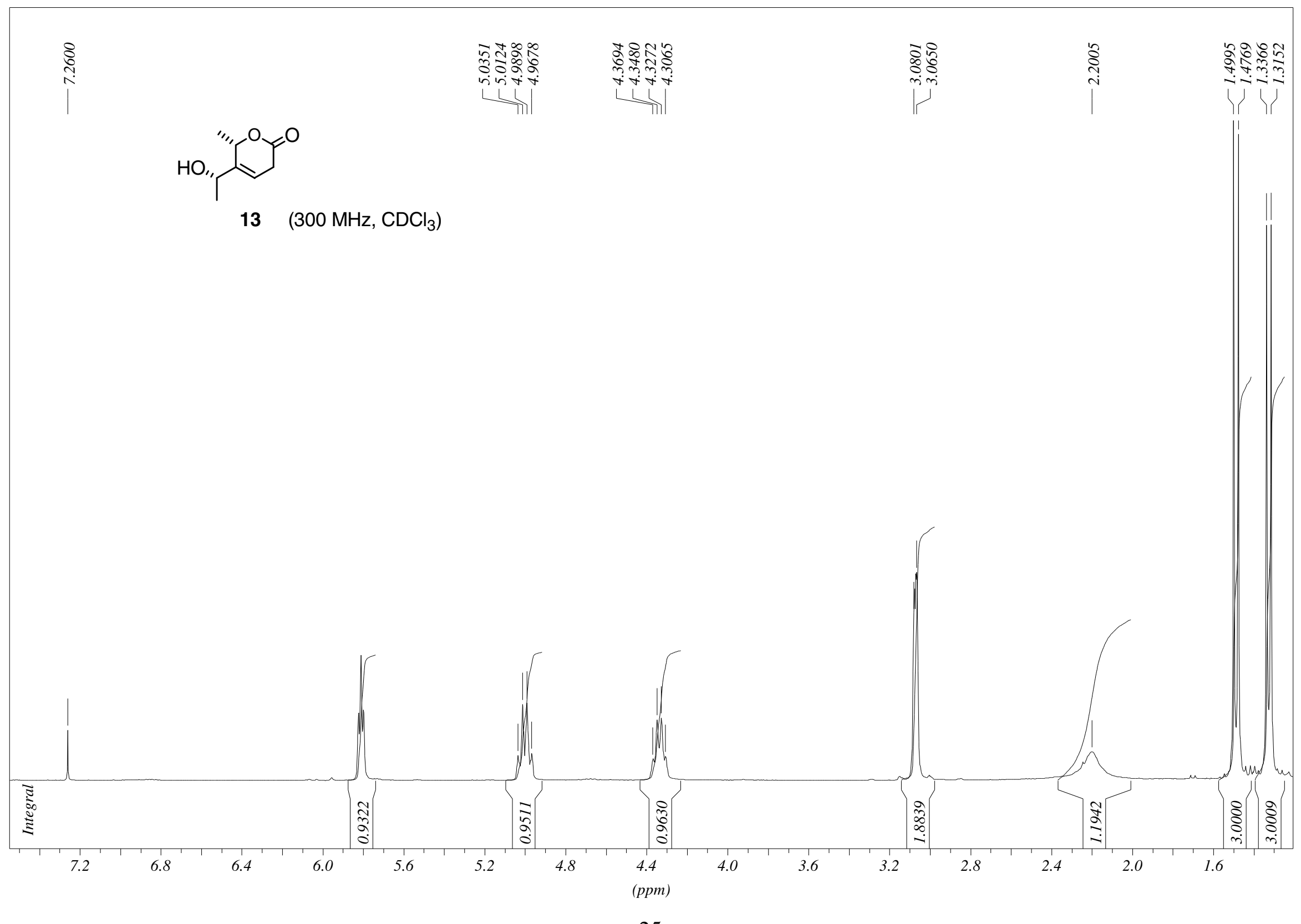




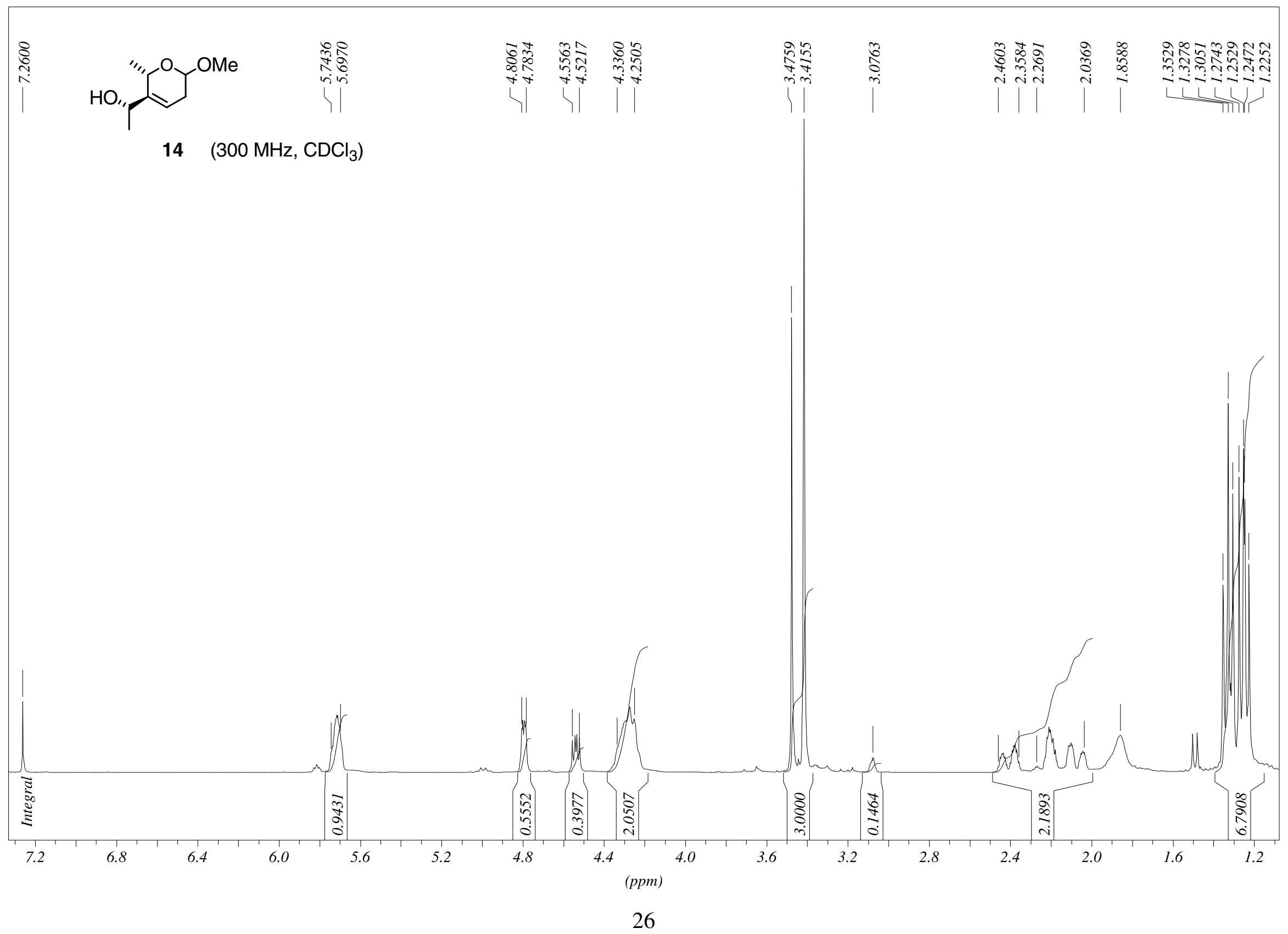




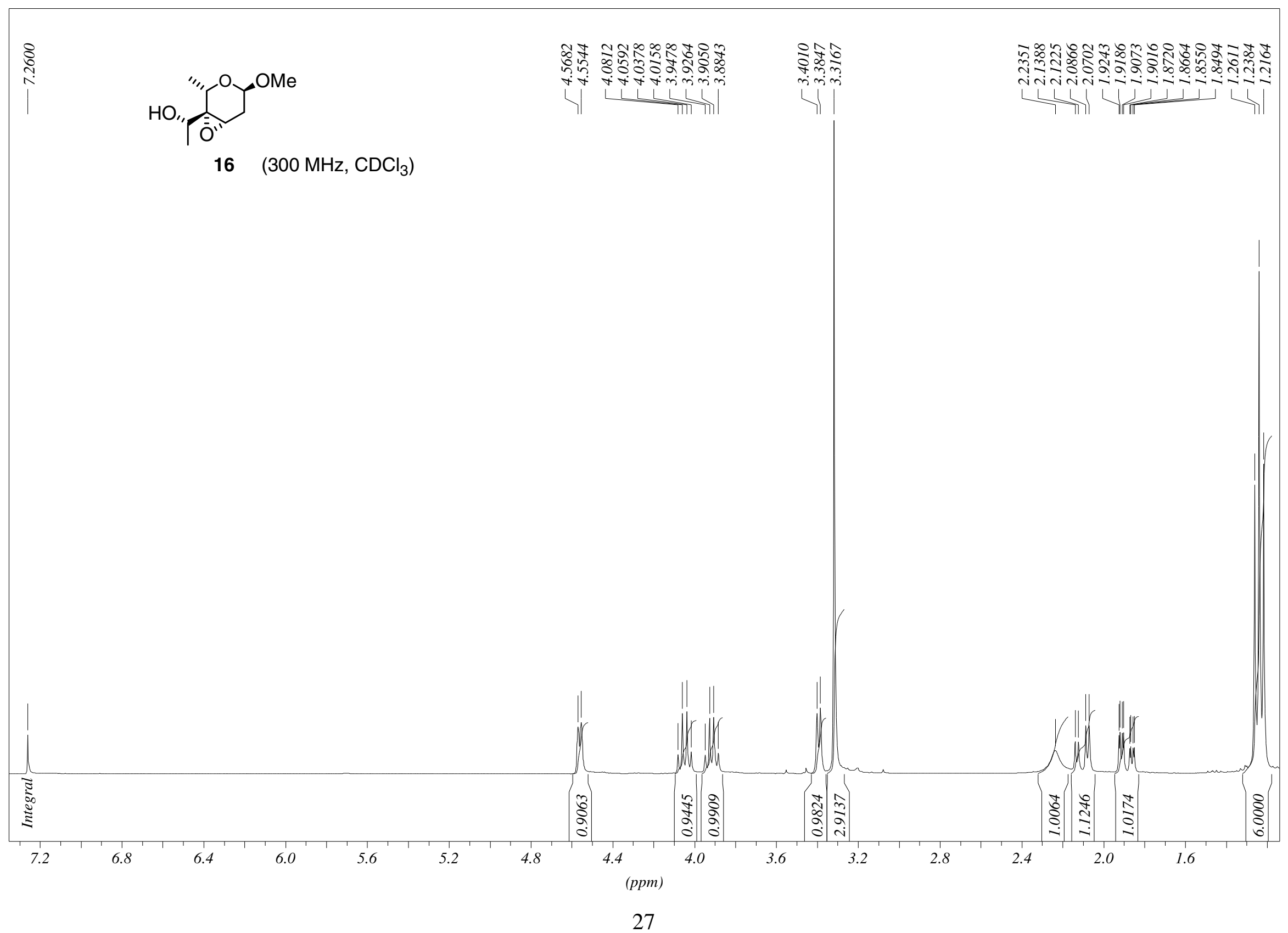




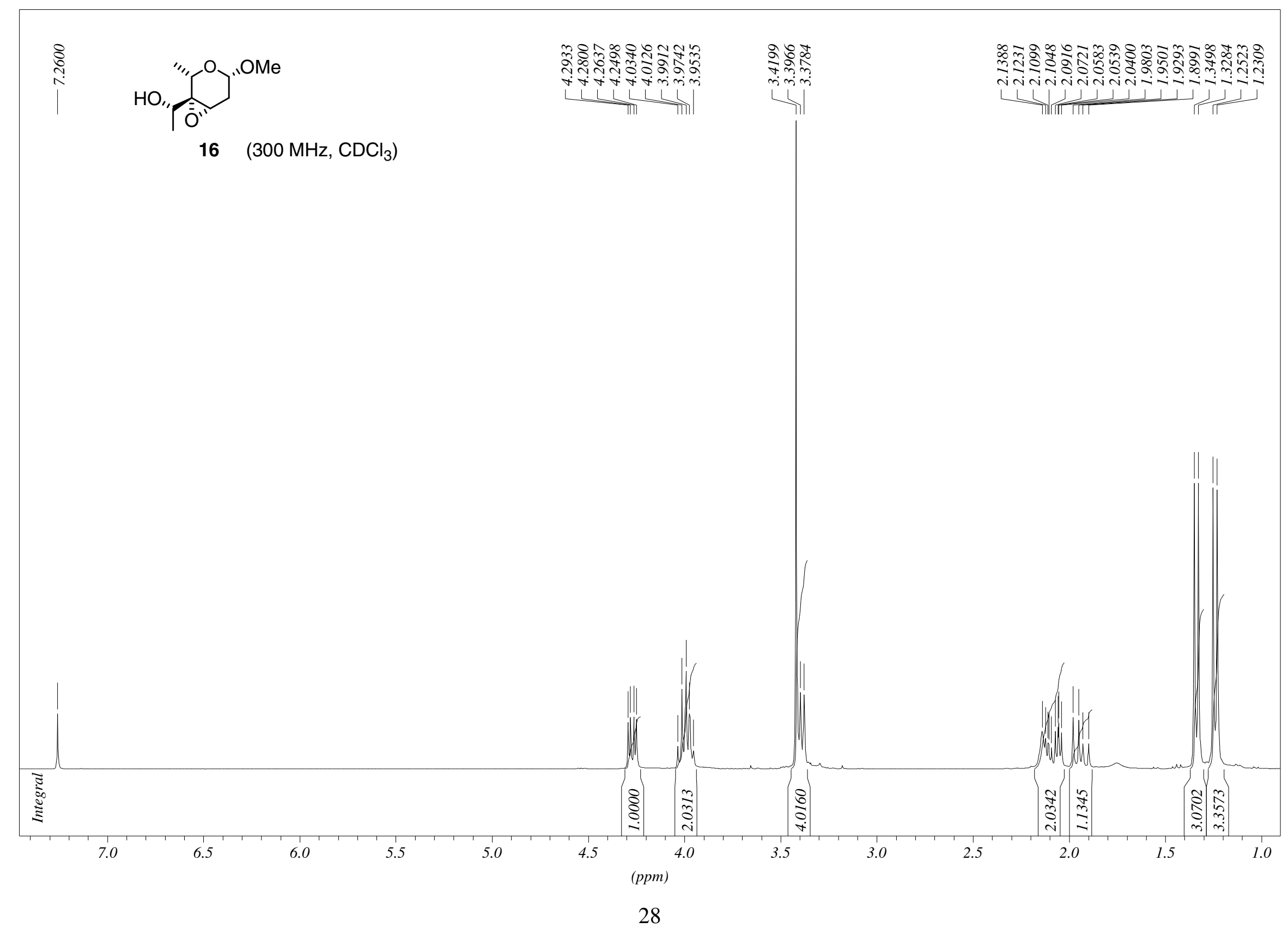




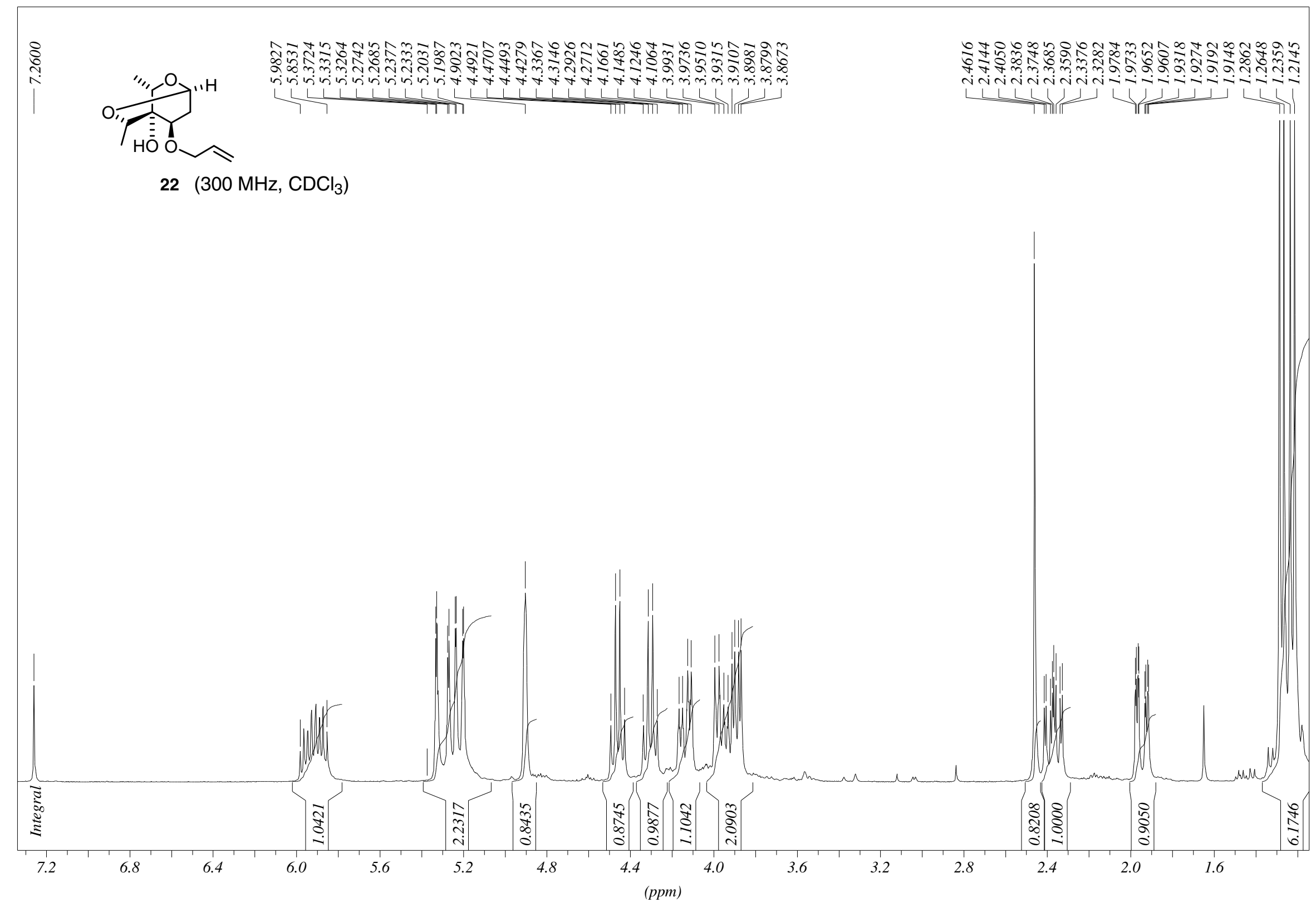




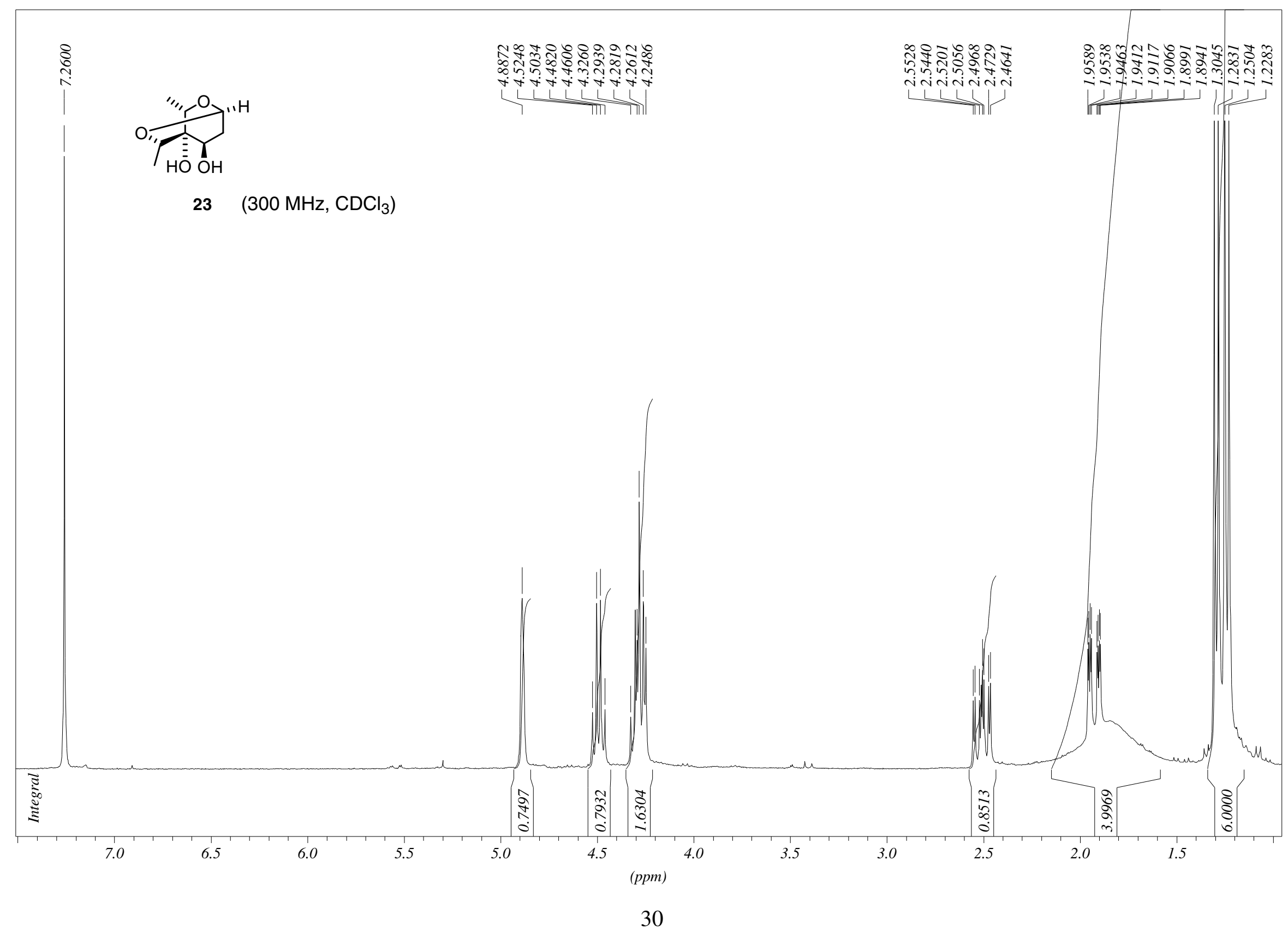




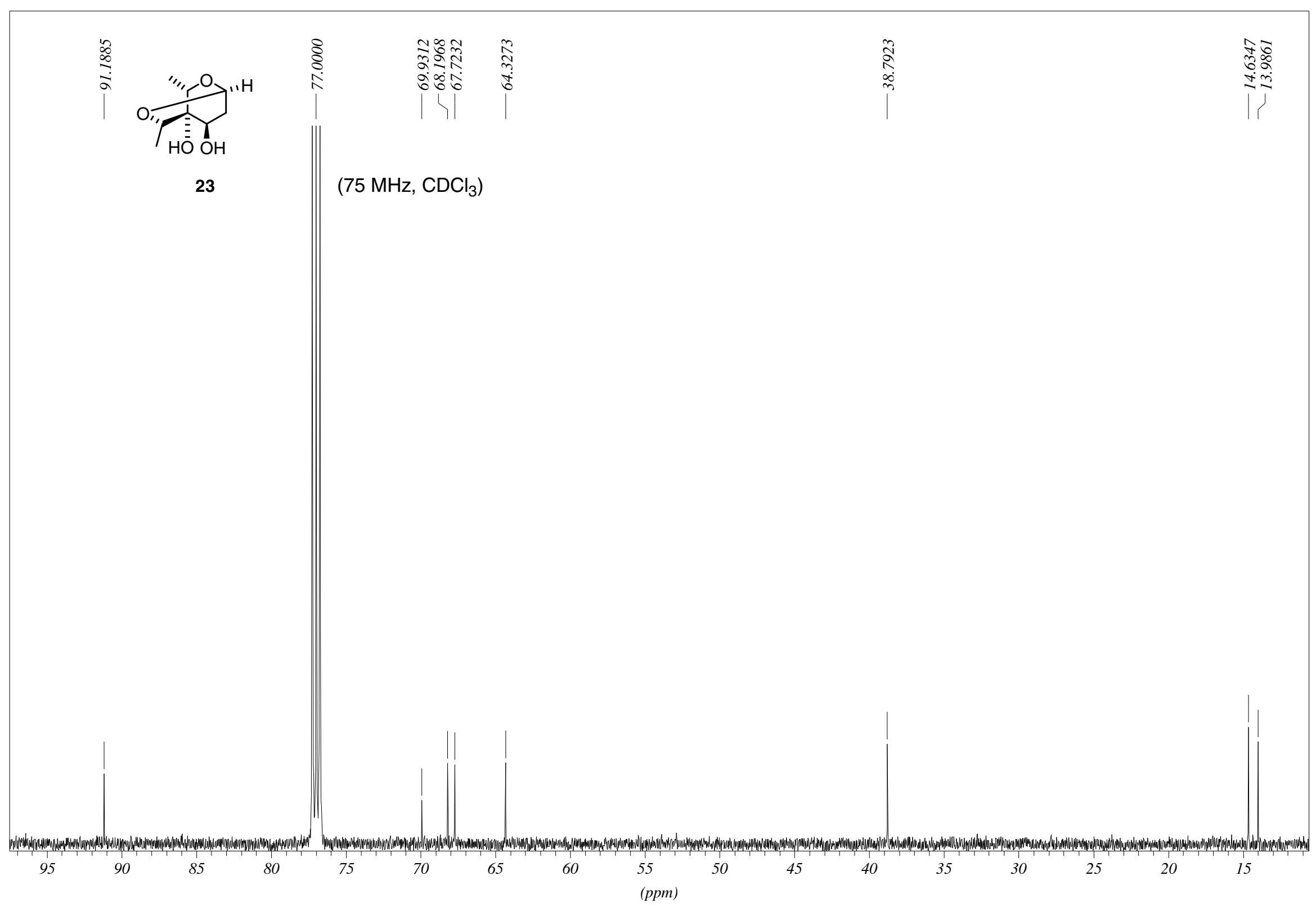




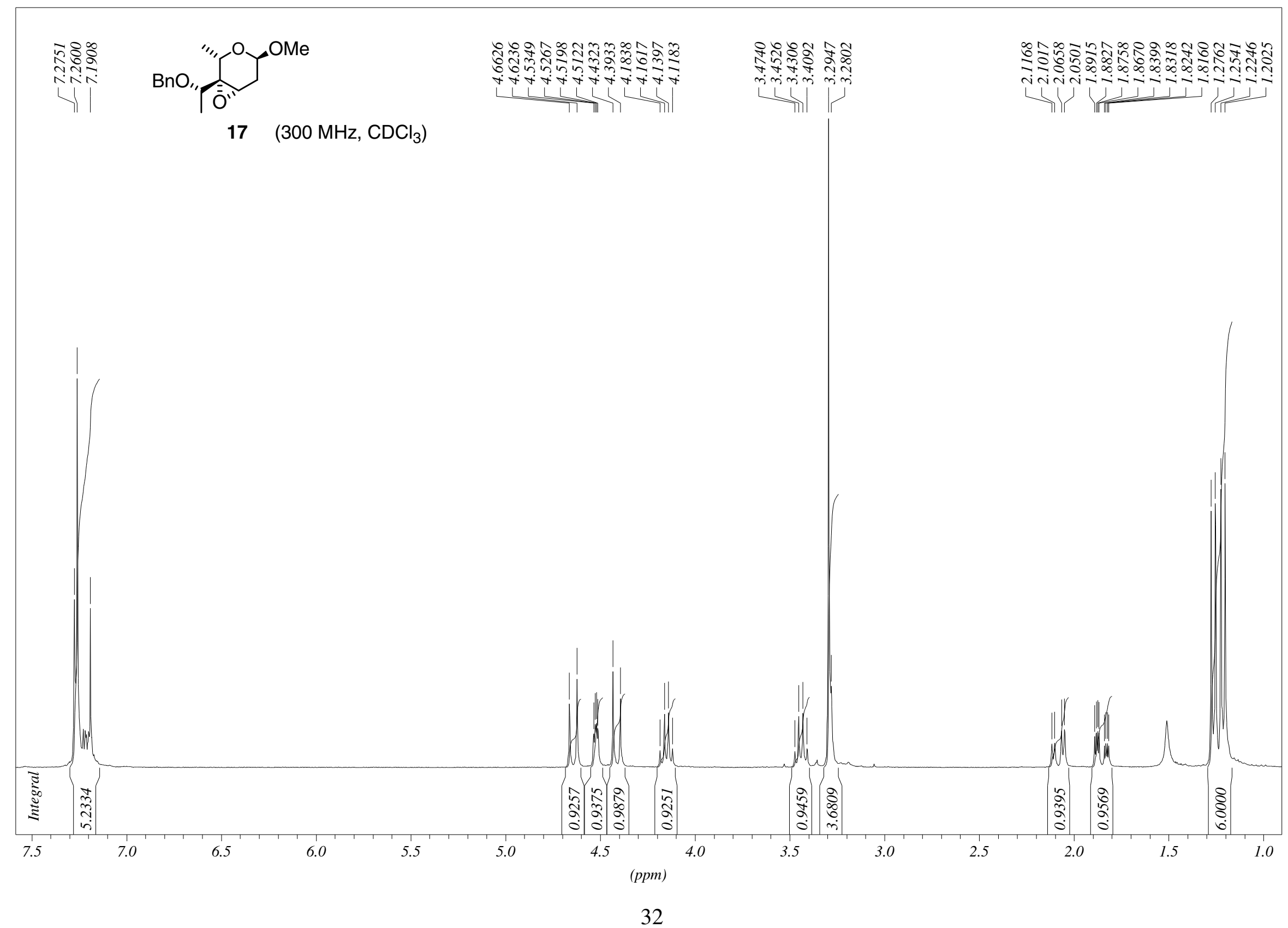




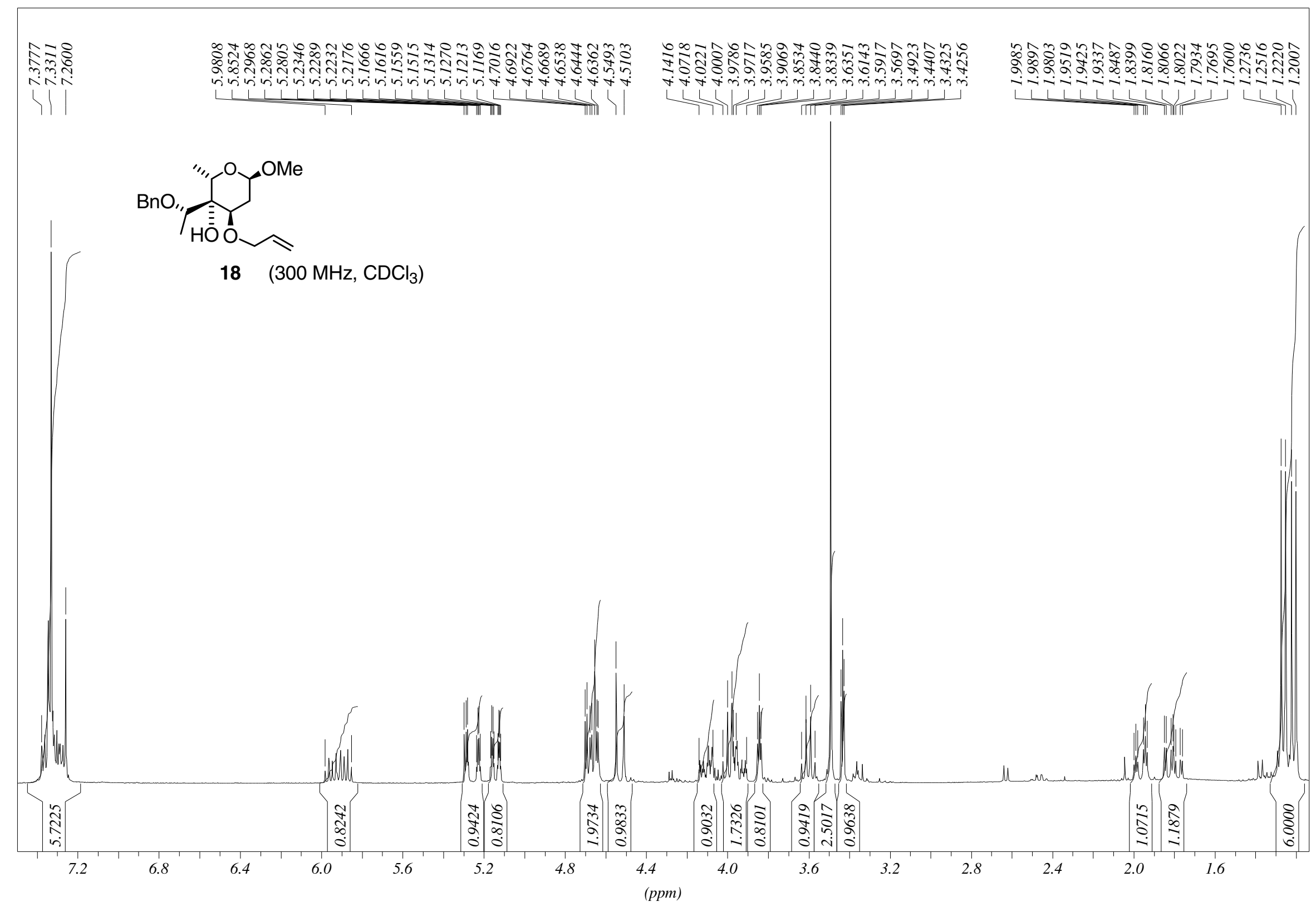




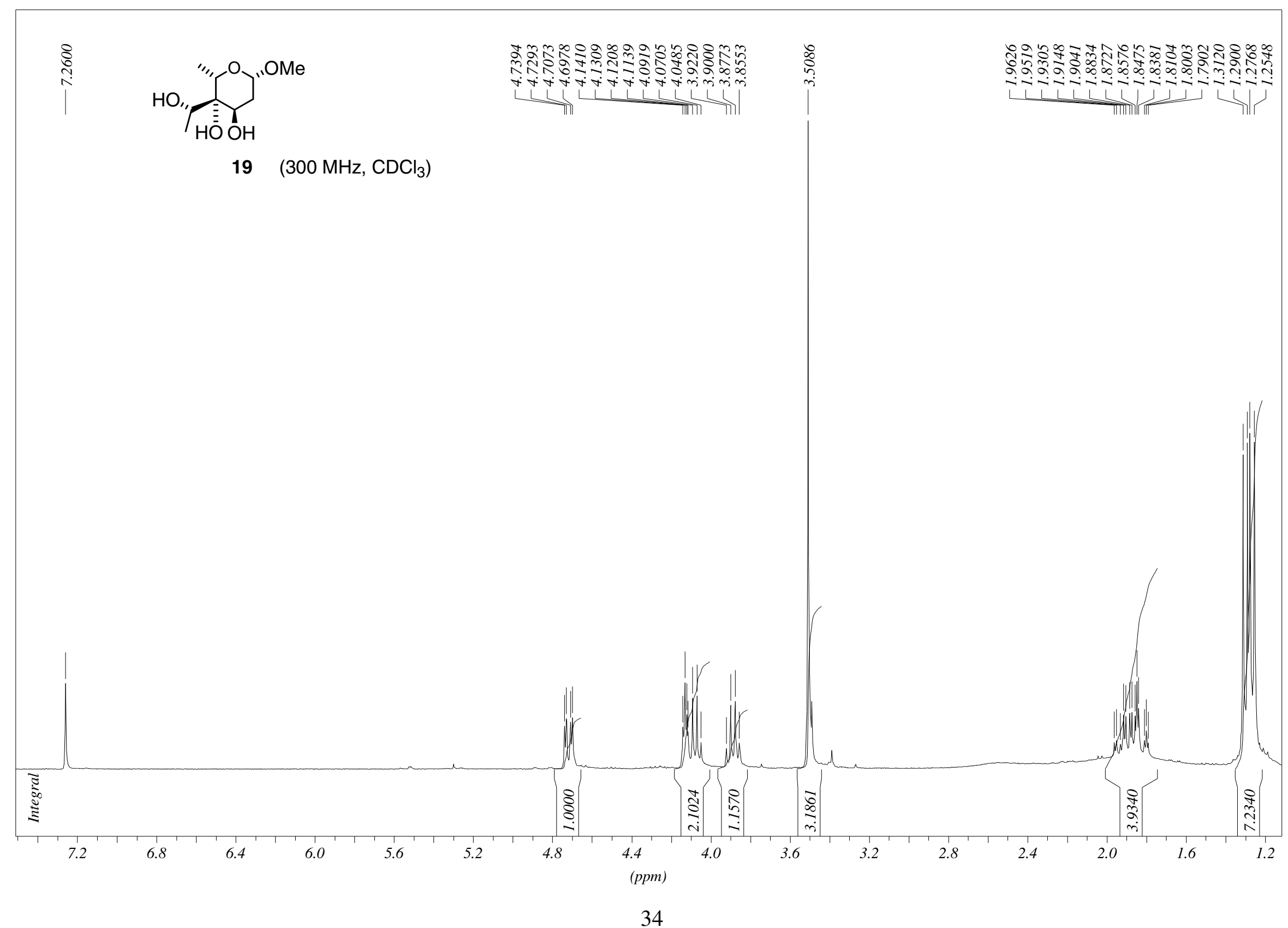




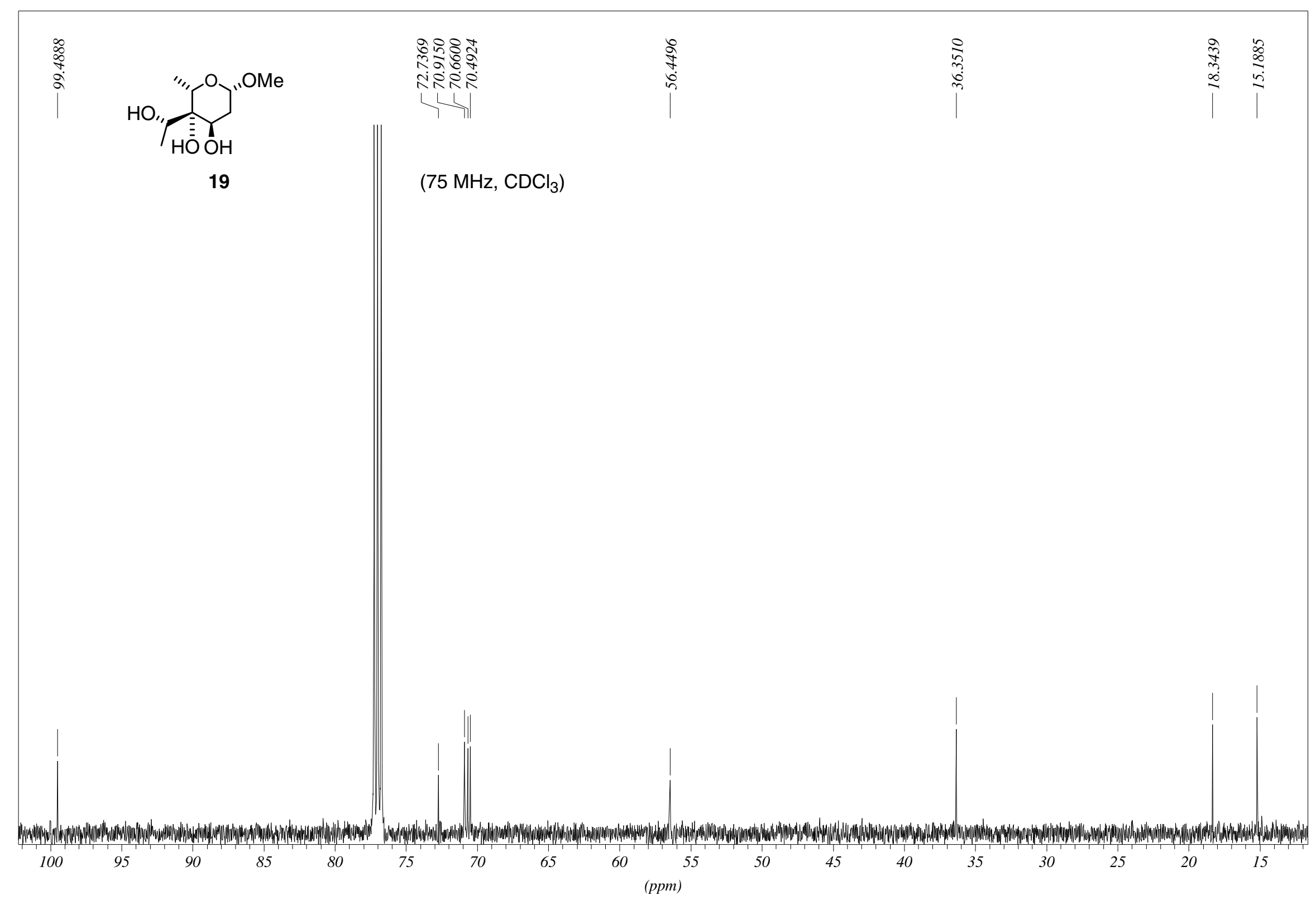




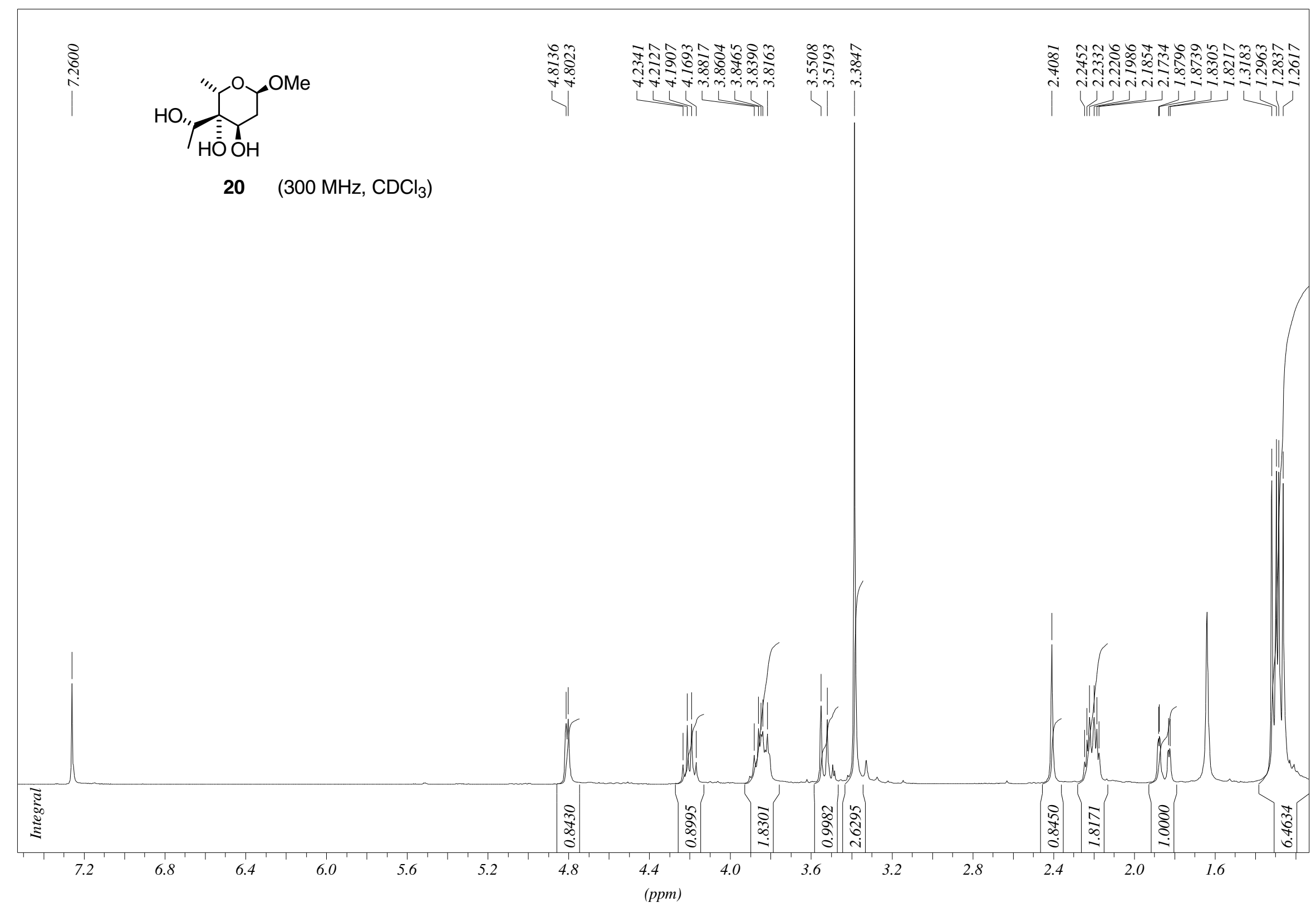

36 


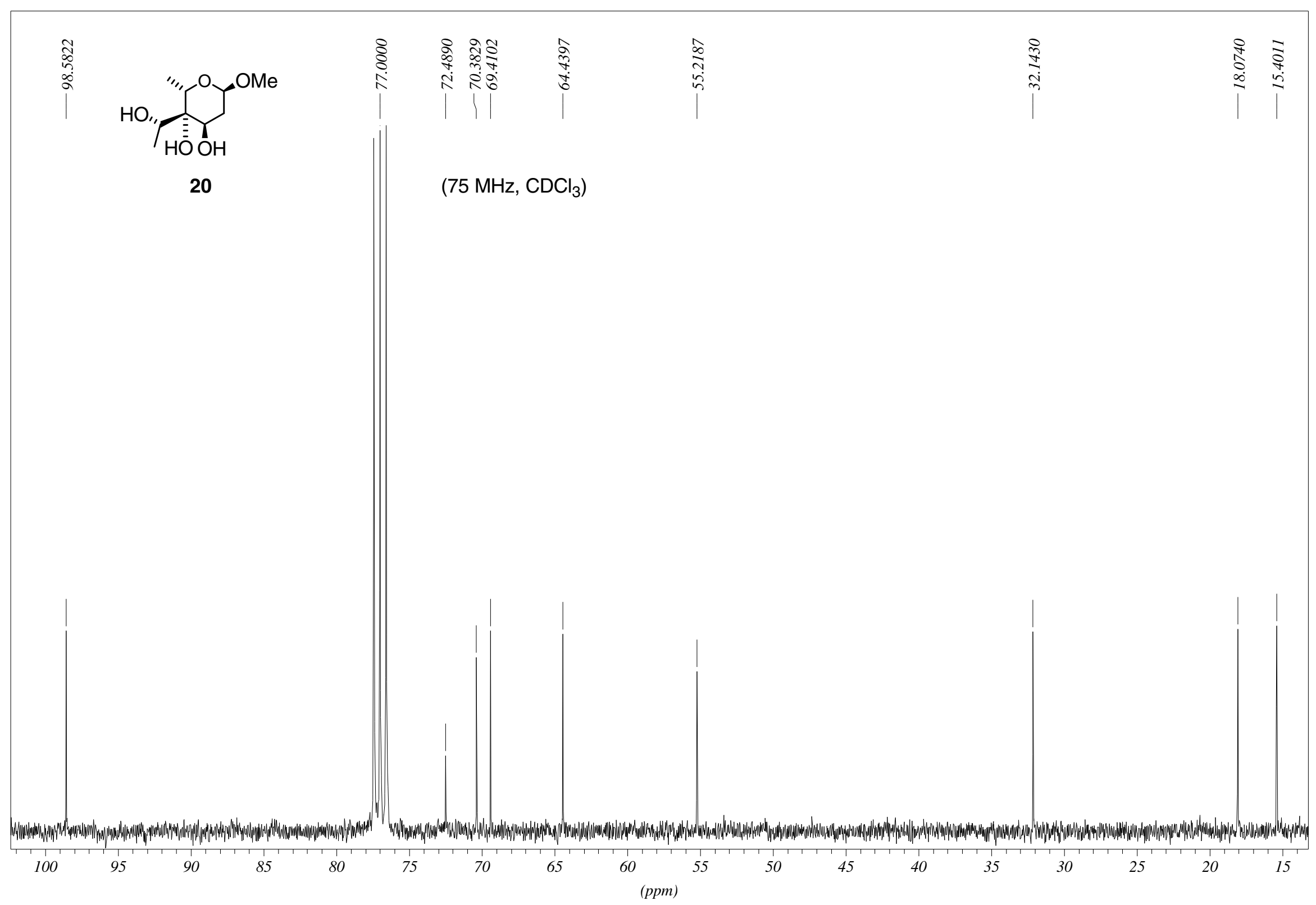




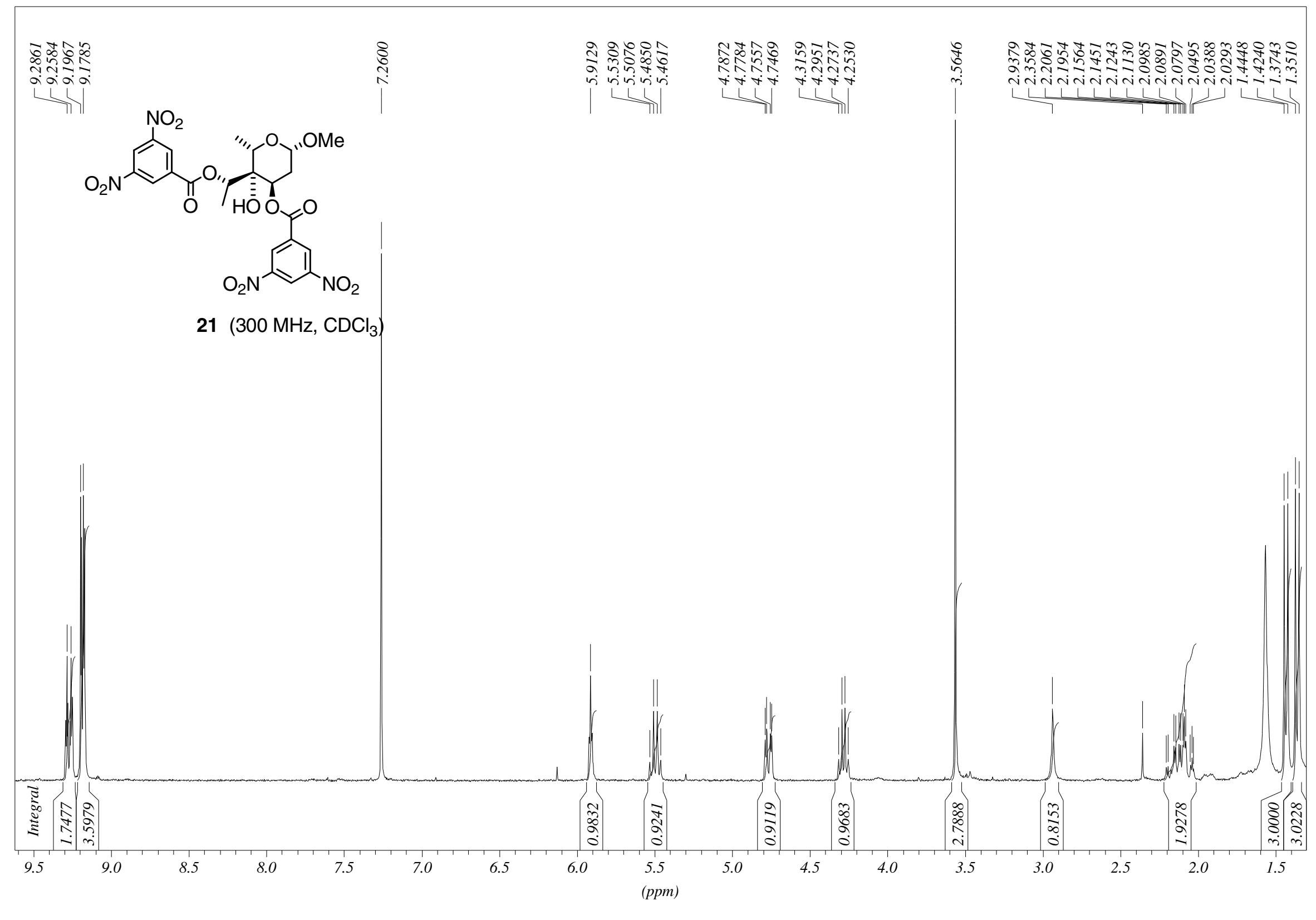




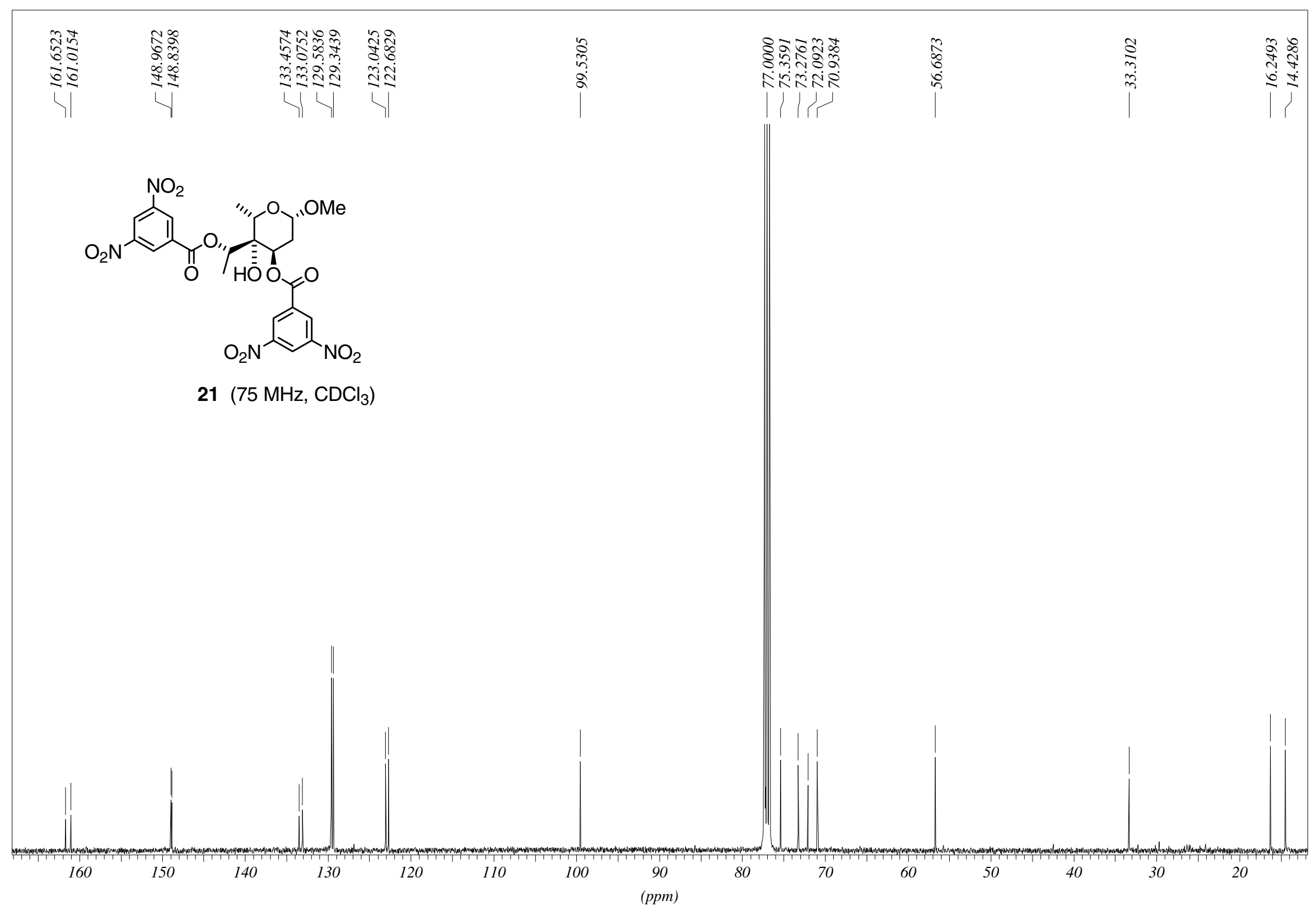

